\title{
田
}

\section{Assessing peace and conflict}

\section{potentials}

in the target region of the GTZ Central Asia and

Northern Afghanistan programme to foster food

security, regional cooperation and stability

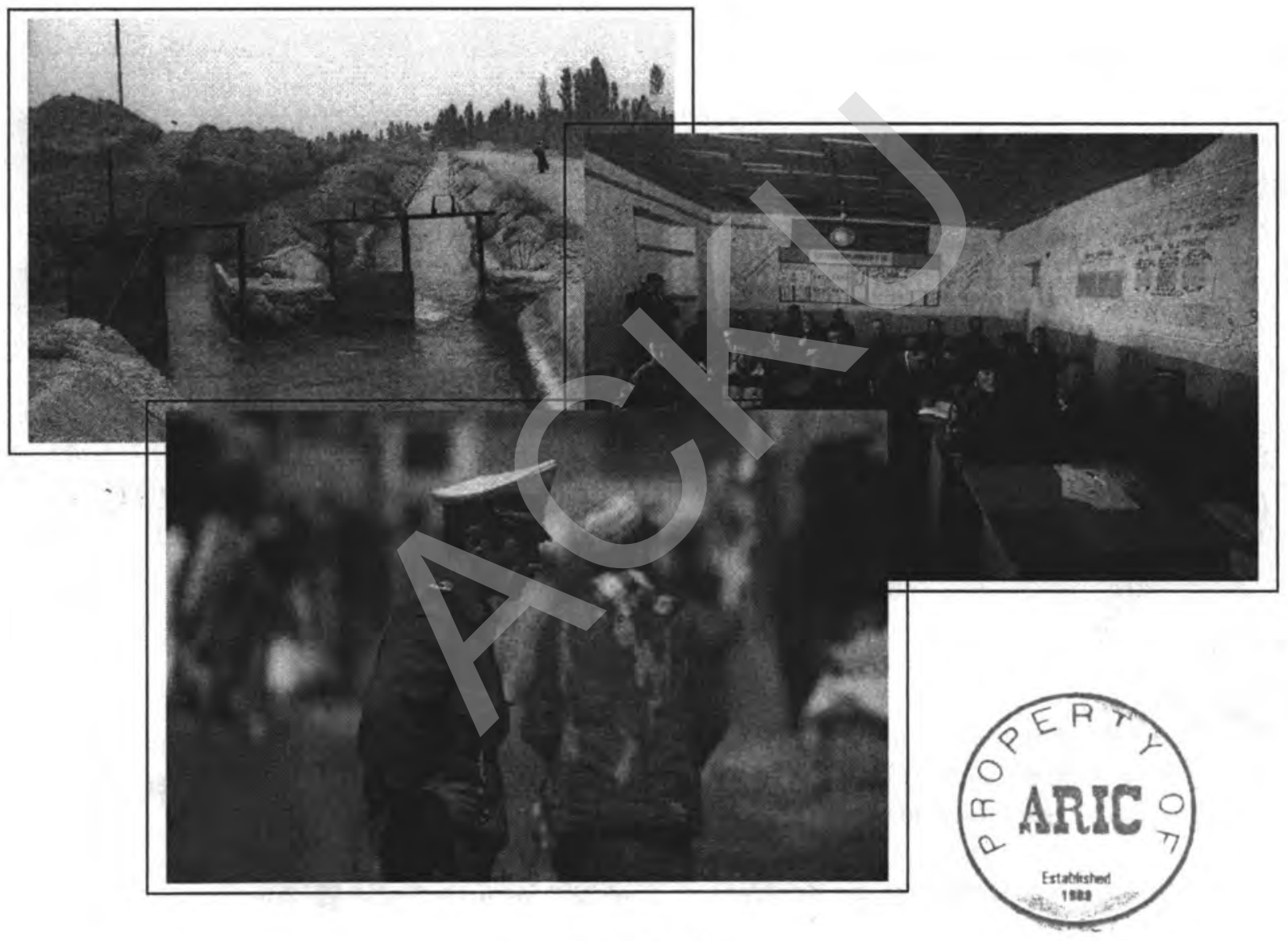

April 2004

Jan Koehler

广ARC

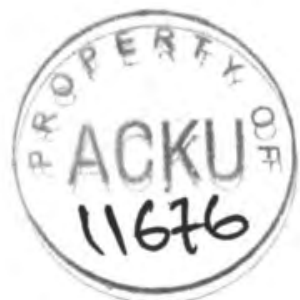




\title{
PREFACE
}

This is the integrated report on the results of three parallel research projects conducted in the GTZ "Promoting Food Security, Regional Co-operation and Stability" Programme target regions in Afghanistan, Kyrgyzstan and Tajikistan.

The findings are to be used by the GTZ Programme and its implementation partners AKDN and MSDSP/AKF.

Three one-week training workshops in Batken, Dushanbe and Faisabad preceded the fieldwork. The team leader, assisted by the respective local research consultants, introduced the research agenda, key concepts to be used and the methods of fieldwork and analysis to be applied. Professional trainers from IDEA Consultants, Berlin, facilitated the three workshops.

Fieldwork was conducted between August and November of 2003 in four districts of Batken Oblast, Kyrgyzstan, in seven districts of Afghan Badakhshan and in three regions (seven districts) of Tajikistan. The following team leaders and research consultants guided the implementation of the fieldwork:

\author{
Afghan Badakhshan \\ Romin Fararoon (AKDN, country team leader) \\ Kristóf Gosztonyi (FU Berlin, research consultant) \\ Marc Theuss, (AKDN, country team leader, part time \\ participation) \\ Batken, Kyrgyzstan \\ Daniel Passon (GTZ, country team leader) \\ Azamat Temirkulov (for ARC Berlin, assistant) \\ GBAO, Rasht Valley, Shurabad in Tajikistan \\ Kishwar Abdulalishoev (MSDSP, country team leader) \\ Christoph Zürcher (ARC Berlin, research consultant) \\ Gunda Wiegmann (for ARC Berlin, assistant)
}

The GTZ Programme in Dushanbe and in Batken and its partners MSDSP and AKDN provided support. Jan Koehler (ARC Berlin, team leader) was responsible for the overall research and was in charge of the general supervision.

The report was written by Jan Koehler with contributions from Christoph Zürcher.

Contact:

ARC Berlin

arc@arc-berlin.com

http://www.arc-berlin.com 


\section{Executive Summary}

This report integrates the results of three individual empirical research projects conducted in the GTZ "Promoting Food Security, Regional Cooperation and Stability" Programme target areas in Afghanistan, Kyrgyzstan and Tajikistan and puts them in the regional context of the GTZ Programme.

\section{The structure of the report}

The introduction to the research context and the explanation of the methodology used make up the first part of the report. The introduction explains the context of the research within the development strategy of the German government to target food security and conflict transformation as core aims in an integrated strategy. The report then moves on to introduce the core concepts used in the research and explains the methodology used for the empirical research and the analytical tools applied.

The second part of this study analyses the main clusters of conflict identified (conflict arenas) in cross-regional perspective. First, the conflict arenas are identified and analysed for the target regions. Then, available and appropriate measures to counter the specific conflicts are discussed.

The report concludes with recommendations for the integrated strategic planning of development activities in the Programme's target region.

We confine this executive summary to the second and main part of the study, namely the conclusions drawn from identifying and analysing most relevant conflict arenas.

\section{Framework conditions}

The framework conditions of peace and conflict for the implementation of the Programme vary between the target regions of the three countries under scrutiny.

In Batken, Kyrgyzstan, the main issue is development in the context of suboptimal conflict management with regard to the distribution of, access to and utilisation of natural resources both on a community level and in relation to neighbouring countries. The situation is marked by dynamics that lead periodically to the aggravation of political and social tensions (e.g. demonstrations, roadblocks), particularly in the vicinity of complex border regimes, but major violent conflict is neither likely nor anticipated.

In Tajikistan stability is achieved not by participative political processes but by a strategy of co-opting opponents into a centralised, vertical system of patron-client relations, controlled by the political elite. Conflict over power, resources or meaning 
is not processed by state or by civil society institutions; conflict is either decided by network-access to power or blocked and left in limbo. The stability achieved is therefore stagnant and prevents sustainable development with regard to conflict transformation, local governance, and the empowerment of civil society. Such changes are perceived as endangering the very system stability which has been achieved. Violent conflict is unlikely as long as this system of governance by patronage and cooptation remains unchallenged.

In Afghan Badakhshan the situation is highly dynamic with regard to the main economic and political factors influencing conflict processes. The local economy that was near despair in recent years due to a combination of war and drought has improved significantly recently, but this is mainly due to the opium poppy boom. The region therefore faces the risk of a sharp decline with the initiation of likely interdiction measures. Politically, a concerted effort at state building "from scratch" is taking place and entrenched informal power holders are on the defensive - though they are far from displaced as yet. The increasing dependency of vast parts of the resource-poor population on the opium poppy economy encourages the formation of new relations of political patronage that may have a future impact on the power balance in the region. The threat, and sporadic application, of violence is still part of the political economy of conflict in Afghan Badakhshan. Large-scale armed clashes have, however, not occurred over the past two years and violence with fatalities in conflict processing has clearly been on the decline.

\section{Conflict potentials}

In this study we do not treat conflict and peace as conceptual opposites. Rather, we understand peace as the ability of society to process arising conflict in a reliable, predictable and non-violent way and contraposition this by violent or disruptive conflict processing.

The most important observation with regard to conflict transformation and stability is that there are currently no large-scale violent conflicts in the programme area. This is a significant change from the time when the "Food Security and Regional Cooperation" Programme was designed. These changes are marked by (a) the fall of the Taliban government, with the military defeat of associated militant Islamist groups penetrating into Tajikistan and at times Kyrgyzstan, and the military presence of an international force in Afghanistan; (b) stabilisation of uncontested central rule in Tajikistan; and (c) the sharp rise in international attention on the Ferghana valley after the attacks of 11 September 2001.

\section{Political conflict arenas}

The research identified modes of local governance and border related issues as critical conflict arenas in the target region of the Programme. 
Local governance refers to the way political and economic power is organised at the local level and how this organisation of power affects society. Hybrid arrangements between official local government, official state and non-state bodies of self-government and informal power holders were found to have a strong impact on the occurrence and processing of conflicts in all regions. Particularly in the regions marked by weak central state control, these modes of local governance are paramount in determining prospects for conflict transformation.

The problem is most acute in the project regions of Afghanistan and Tajikistan. In Afghan Badakhshan local governance takes place within a state, which is still contested, or even without direct state interference. In the target regions of Tajikistan different modes of bad local governance have been stabilised in a weakly institutionalised but uncontested state.

Local governance in all target regions fails to provide or facilitate the provision of institutional cornerstones for conflict transformation:

$\rightarrow$ negotiated agreements between conflicting parties, or binding decisions on conflicts by specialised institutions, according to accepted and well known procedures;

$\rightarrow$ formalisation of the agreements and decisions into binding contracts;

$\rightarrow$ implementation of the agreements and decisions;

$\rightarrow$ monitoring so that parties stick to the agreements and 'play by the rules';

$\rightarrow$ a credible sanction mechanism to protect negotiation, procedure and implementation against foul play and rule breaking;

$\rightarrow$ a policy of transparency with regard to the above mentioned mechanisms.

In essence, this report suggests that an integrated strategy targeting conflict transformation in the Programme region must focus on strengthening these cornerstones of "good conflict" with the tools available to food security centred development.

Within the given research design we are interested in the impact borders have on conflict risks and the conflict processing capacities of communities affected by borders both as physical infrastructure and in the institutional sense of border regimes.

Two sets of borders need to be distinguished in this analysis: The borders between Afghanistan and Tajikistan, and the borders in the Ferghana valley between Tajikistan, Uzbekistan and Kyrgyzstan. Problems and opportunities vary widely, and there cannot be a single approach.

On the Afghan-Tajik border there are two main risks to cross-border stability. (1) The failure of state building in Afghanistan and resumption of civil war; and (2) the 
uncontrolled effects from the relaxation of the border regime and the encouraging of contact between the border communities.

The problem with border regimes in the Batken target area is of a very different nature. The main concern for conflict transformation is (1) the irrational patchwork arrangement of a multitude of exclaves of two neighbouring countries on its territory, with only partially demarcated borders; (2) political manipulation and corrupt misuse of the border regime; and (3) the lack of effective cross-border institutional arrangements to solve local conflicts locally.

The border regimes of national states as causes of conflicts are beyond the reach of GTZ Programme tools. The Programme can influence the policy of national governments only indirectly, by lobbying for political persuasion from the German government or by co-operating with lead agencies of regional diplomatic standing. Programme activities can, and should, however, strengthen the local capacities of communities to deal with tensions and problems arising around border issues in a peaceful and predictable way.

\section{Economic conflict arenas}

The research identifies three conflict arenas related to the field of economic activity of communities in the target region. They are competition over the natural resources water and land, but also opium poppy related economic activities.

The aggravation of conflict about limited natural resources is conditioned by three factors: (1) the lack of availability (particularly of arable land); (2) the arbitrary, power-locked or simply ineffective organisation of access to and utilisation of the resource (both water and land); and (3) the negative impact of other conflict arenas on unchecked resource competition, most importantly the complex border regimes in Batken, power locked local governance in Tajikistan and Afghan Badakhshan, and social factors like settlement patterns, destructive coping strategies and, to a lesser extent, intercommunal prejudice and practices of exclusion.

This study shows that conflict transformation or escalation around the competition for natural resources is influenced less by objective scarcity and more by the local organisation of scarcity (the institutionalisation of coping strategies). A positive impact of material and technical measures on conflict transformation is often conditional on prior investment in organisational development, making technical improvements possible in the first place and sustainable in the long run. Organisational development and institutional change is, from the perspective of local communities, usually more costly than technical improvements. Donor co-ordination is essential in order to provide coherent incentives for communities to invest in organisational change.

The conflict analysis in the target regions established drug related issues as the main conflict arena within the informal and criminal economic sector for Tajikistan and Afghanistan. The arena includes the production, refining, trafficking and consumption of opium poppies and heroin. It is closely connected to the arenas of 
"border" and "patterns of local governance" and the aspect of state building in particular.

The relationship between the opium poppy economy and conflict is less clear and differs from commonly held expectations. In Afghan Badakhshan the rise in production and widening access to this economy thus far has instead relaxed pressure on other resources within diverse livelihood strategies (e.g. arable land, credit, livestock, work migration). From a local viewpoint it appears to be an important coping strategy for the resource poor and an attractive strategy for further accumulation for the resource rich. The immediate risk for conflict aggravation around this criminal economy is connected to a combination of a growing dependency of the resource poor on poppy cultivation and its new patrons with imminent interdiction measures. We expect that any successful but untargeted enforcement programme would certainly have a very negative effect on the debtdependency and food security of this resource poor group that only recently managed to upgrade their survival strategy to coping thanks to their access to fringes of the opium poppy economy.

Opium poppy and heroin trafficking via Tajikistan causes serious security problems for local communities in the immediate vicinity of border trade routes. However, the professionalisation and concentration of the trade in recent years has reduced the general impact of this economy on conflicts at a community level. Big business bypasses local communities. Thus, in comparison to the free-for-all opium trade of the 1990 s, communities in rural Tajikistan are less affected today by drug related conflicts.

With regard to the drug economy in parts of the Programme's target region, we suggest that an integrated approach is needed, combining immediate and mid-term enforcement and emergency aid measures with long-term development strategies.

\section{$\underline{\text { Social conflict arenas }}$}

In the rural regions researched, social issues were not identified as primary conflict arenas. Issues relating to youth, tension between the generations, issues regarding new dynamics in gender relations, and issues concerning exclusion and discrimination against identity groups of ethnic, religious, or regional belonging did, however, surface as secondary conflicts.

Political entrepreneurs misuse prejudice and ignorance to justify the exclusion of minority groups from access to important resources. In the course of escalating conflicts such politicised social differences are used to justify amoral action against segments of society. While social difference may be an important ingredient in conflict dynamics it is, however, very rarely the dominant source of violent conflict. The assumption that "social conflict" needs to be seen in relation to other conflict arenas, particularly resource competition, has been reinforced by the research.

Conflict transformation with regard to gender, generation and minority relations is a complex issue devoid of any quick fixes. These relations are deeply entrenched in 
powerful tales of culture and tradition. Any attempts to foster change in these relations will find that they change only very slowly and incrementally; they are fortified against quick adaptive change by the symbolic power of culture.

Advancing conflict transformation in the Programme region via strategies targeting the changing relations between the generations, between the sexes and between identity groups can be successful if they are long-term and focus on modest, achievable goals.

We argue that it is essential to meet local society where it is, rather than confronting local communities with arcane approaches to modernisation. All target areas, including Afghan Badakhshan, have their own historic experience with periods of modernisation to connect to. Adapted modernisation, i.e. modernisation that is sensitive to local culture, is nothing new to communities in the target regions.

The most important incentive for individuals in traditional societies to engage in changing the traditional patterns of social organisation is the feeling of participation in shaping ones own future - the awareness of life-opportunities must be connected to the awareness of the need for change. Directing the focus of the Programme on the way young people become aware of and realise their life-opportunities is an important ingredient in an integrated strategy for the region. Education, access to information, vocational training and enhanced (physical and social) mobility are cornerstones for such a strategy.

\section{Local capacities and limits for peace and non-violent conflict processing}

The snapshot this research provides of the Programme region finds more stability than expected and a (widespread) absence of violent conflict in the presence of a multitude of risk factors. The causes identified for this relative non-violent local and regional stability are, unfortunately, no reason to relax the focus of development strategies on conflict transformation for the region.

First, we find that local informal or formal institutions are capable of keeping peace within the community when they are protected by social control and self-policing. This is the case with the majority of village communities in the project area. The problem with this kind of conflict processing is that its effective scope is confined to the village. The capacity for the implementation of decisions, monitoring compliance and sanctioning defiance is limited to the scope of the eye of the village and sanctions of reputation; i.e. are limited to the community. Such institutions are not equally suitable for stable inter-communal conflict transformation. The results of the Afghan Badakhshan and Tajikistan field research in particular show that decisions reached on intercommunal conflicts often reflect the power relations between conflicting parties rather than legal principles. Conflict is left in limbo or (temporally) decided by power. Without a supra-communal institution, the formalisation of binding decisions does not take place. Ideally, this supra-communal institution regulating conflict is the state (rather than commanders or local strong 
men). In this respect, the lack of the state at the local level is a critical deficit in all three countries.

The analysis therefore finds that connecting local capacities of conflict management to local state institutions must be a strategic goal for Programme activities. We have to acknowledge, however, that this goal is difficult to accomplish in parts of the target areas. The stability of the political system achieved in Tajikistan after the Civil War is marked by patronage and cooptation of local elites into administrative positions. Local state institutions are not only weak; they are also undermined by this parallel and vertical system of network-governance. In Afghanistan local state institutions to which it is possible to connect, are only in the process of re-emerging. In this process a crucial goal of development initiatives as part of state building must be to prevent the local state bodies from following the example of Tajikistan style stabilisation. Since neither local civil society nor donor activity can replace the state in its responsibility for providing security and conflict processing there is, despite these constraints, no sustainable alternative for communities other than to connect to the local state administration. Strengthening the lobbying power of communities vis-à-vis the networked state must therefore remain a strategic goal of the Programme. 


\section{Table of content}

1 Executive Summary __ ii

2 Introduction

2.1 The context: development, change and conflict

2.2 Food security, regional co-operation and stability in the programme region 7

2.3 Objective of the report

3 Concept and methodology

3.1 Conflict 10

3.2 Methodology 12

3.2.1 Why local analysis of conflict and peace potentials?

3.2.2 Preference to qualitative methods __ 14

3.2.3 Structuring the research and analysis _ 15

4 Conflict Arenas and Conflict Transformation in the Target Areas of Afghanistan, Kyrgyzstan and Tajikistan _ 18

4.1 Country context

4.I.1 Afghanistan 18

4.1.2 Tajikistan $\longrightarrow 19$

4.1.3 Kyrgyzstan — 20

4.2 Political arenas _ 21

4.2.1 Arena: Local modes of governance ___ 21

4.2.2 Arena: Border related issues _ 30

4.3 Criminal economy related conflict arenas _ 36

4.3.1 Arena: Drugs __ 37

4.4 Natural resource related conflict arenas

4.4.1 Arena: Water $\quad 42$

4.4.2 Arena: Land $\longrightarrow 45$

4.5 Social conflict arenas

4.5.1 Youth 53

4.5.2 Gender _ 55

4.5.3 Minorities \& Discrimination 56

5 Recommendations for an integrated strategy on conflict transformation in the

Programme region 59

5.1 Recommendations for activities in the Programme region

5.1.1 Donor capacity building, enhancing the effectiveness and synergy of development initiatives targeting conflict transformation__ 59

5.1.2 "Soft" measures _ 61

5.1.3 "Hard" measures 63

5.1.4 Understanding conflict and using information for planning and project adaptation -65

5.2 Recommendations on regional cooperation and regional stability

5.2.1 Potentials and limits of regional cooperation in the context of conflict transformation 68

5.2.2 Geographical re-orientation of target regions for regional co-operation _ 68

5.3 Recommendations on PCIA 71

5.3.1 Impact Monitoring, measuring, adapting __ 71

6 References__ 74 
7.1 Term of Reference Team Leader

7.2 Activity plan local research teams and team leader

7.3 Buzzwords and concepts

7.4 Matrix

7.5 Identification and prioritization of research sites according to conflict arenas 7-41

7.6 Fieldwork tools

7-43

7.6.2 Field diary

$7-43$

7.6 .3

Guided interview

$7-43$

7.7 Programme Planning Matrixes_ 7-47

7.7.1 Adapted AKF offer to GTZ

7.8 Unpublished reports and documents referred to

7.8.1 Police report Batken $7-53$

7.8.2 Excerpt from interview with Dovlad Mohamad, Wolliswol (Governor) of Jerm district in Afghan Badakhshan, conducted in Baharak on the $24^{\text {th }}$ of October 2003 by Romin Fararoon, Kristof Gozstonyi and Jan Koehler $7-60$ 


\section{Glossary and Abbreviations}

\begin{tabular}{|c|c|}
\hline AA & Auswärtiges Amt (The Federal Foreign Office) \\
\hline AKDN & Aga Khan Development Network \\
\hline AKF & Aga Khan Foundation \\
\hline AO & $\begin{array}{l}\text { Ail Okmotu (sub-district; lowest level of local self-government in } \\
\text { Kyrgyzstan) }\end{array}$ \\
\hline ATA & Afghan Transitional Administration \\
\hline $\mathrm{BMZ}$ & $\begin{array}{l}\text { Bundesministerium für wirtschaftliche Zusammenarbeit und } \\
\text { Entwicklung (Federal Minister for Economic Co-operation and } \\
\text { Development) }\end{array}$ \\
\hline CBO & Community Based Organisation \\
\hline CDU & Community Development Unit of MSDSP \\
\hline Commandon & $\begin{array}{l}\text { Dari for commanders, usually referring to informal armed } \\
\text { authorities on local level in Afghan Badakhshan context }\end{array}$ \\
\hline FTI & Foundation for Tolerance International, NGO in Kyrgyzstan \\
\hline GBAO & Autonomous Region of Badakhshan, Tajikistan \\
\hline Hezb-e Islami & $\begin{array}{l}\text { Mujahedin faction led by the wanted warlord Gulbudin } \\
\text { Hekmatyar, Afghanistan }\end{array}$ \\
\hline ICWC & $\begin{array}{l}\text { Interstate Coordinating Water Commission, Central Asian } \\
\text { countries }\end{array}$ \\
\hline IMU & Islamic Movement of Uzbekistan \\
\hline Jamiat-i Islami & $\begin{array}{l}\text { Mujahedin faction led by former Afghan President Burhanuddin } \\
\text { Rabbani }\end{array}$ \\
\hline Jamoat & Sub-district; lowest level of local self-government in Tajikistan \\
\hline Khukumat & Local government at district level, Tajikistan \\
\hline Kishlak & Village community \\
\hline Kolkhoz & Collective farm within the Soviet System \\
\hline KSSR & Kyrgyz Soviet Socialist Republic \\
\hline Mantaqa & regional unit (sub-district), Afghanistan \\
\hline MSDSP & Mountain Societies Development Support Programme \\
\hline NSP & National Solidarity Programme, Afghanistan \\
\hline OIB & Oblast Irrigation Department, Kyrgyzstan \\
\hline $\mathrm{PCl}$ & Peaceful Community Initiative \\
\hline
\end{tabular}




$\begin{array}{ll}\text { PCIA } & \text { Peace and Conflict Impact Assessment } \\ \text { PEU } & \text { Policy Evaluation Unit of MSDSP } \\ \text { RDD } & \text { Regional Dialogue and Development } \\ \text { RID } & \text { Rayon Irrigation Department, Kyrgyzstan } \\ \text { Shura-i Nazar } & \text { the Mujahedin faction of late Ahmed Shah Massoud, } \\ & \text { Afghanistan } \\ \text { Sovkhoz } & \text { State owned farm within the Soviet System } \\ \text { TSSR } & \text { Tajik Soviet Socialist Republic } \\ \text { UzSSR } & \text { Uzbek Soviet Socialist Republic } \\ \text { VO } & \text { Village organisation, Tajikistan. MSDSP initiated institutions of } \\ & \text { self-governance that are aimed at mobilizing the community in } \\ & \text { order to deal with everyday problems by themselves. These } \\ & \text { village organisations generally comprise over } 80 \% \text { of } \\ & \text { households in each village. Members hold monthly meetings } \\ & \text { and pay fees, which contribute to a revolving village } \\ & \text { development fund used for credit and grants for members and } \\ \text { for village-wide projects. } \\ \text { WB }\end{array}$




\section{Introduction}

\subsection{The context: development, change and conflict}

Two interdependent capacities of society are preconditions for sustained development: (1) non-violent and predictable conflict processing is guaranteed (=peace), and (2) the basic needs of relevant parts of the population are secured (=food security and basic infrastructure).

In societies marked by unusual rapid changes of economic, political and cultural framework conditions - so-called transitional societies - a third capacity is key for development: (3) the social ability to adapt and innovate existing institutions, norms and habits to new realities.

Development and aid programmes work in the context of states with limited, nonexistent or distorted capacities. Providing important material and non-material resources in an unstable institutional environment in which the existing rules of access and distribution are either distorted by bad governance or simply not set because of non-governance is a tricky endeavour.

Aid and development organisations are increasingly aware of being affected by conflict even when their strategy is to avoid any involvement in conflict or when there appears to be no conflict of relevance to the intervention. One reason for this is that resources distributed by development organisations may be misused to stabilise local regimes that block development opportunities thus freezing rather than resolving tensions. Another reason may be that the conditions attached to the distribution of resources often contradict local informal rules of distribution, which may actually lead to new conflicts. Furthermore, building new or empowering existing local institutions may trigger changes in the distribution of power that threaten existing stable, though often non-democratic, relations between groups. Such unintentional interplay between development and aid projects and conflict make development agencies call for the integration of "do-no-harm" principles" into project programming and implementation.

\footnotetext{
1 Primum Non Nocere $=$ First Do No Harm, part of the Hippocratic Oath. Mary B. Anderson adapted the concept to development cooperation in crisis situations as a basic principle to account for (Anderson 1999). According to the do -no-harm principle, any unintentional consequences of humanitarian aid and development cooperation should be critically examined and the inadvertent exacerbation of conflicts recognised, avoided and rectified. To this end development actors must be able to review the technical and operational aspects of development projects in terms of their conflict relevance, conflict risks and actual impacts (definition taken from http://www.gtz.de/crisisprevention/english/approach.htm).

Unfortunately, the principle of do-no-harm analysis is much more often quoted in strategy papers and recommendations than actually implemented in development projects.
} 
Recently, many development programmes have been directly addressing the nexus between development and conflict by explicitly aiming to develop the conflict processing capacities of target groups.

For development programmes of the German government the concept of "working on conflict" ${ }^{\prime 2}$ became particularly important since crisis prevention was explicitly marked as one of the main foci of development policy. ${ }^{3}$ Development policy is seen as a part of an integrated strategy of crisis prevention that involves the full range of military, diplomatic, political, and economic tools at the disposal of the government. In this context the task of development policy is to improve economic, social, ecological and political conditions in order to reduce structural causes of conflict and enhance non-violent, constructive conflict processing. ${ }^{4}$

The German Ministry of Development and Co-operation (BMZ) identifies the task as follows: ${ }^{5}$

Development policy can be functional in preventing crises and reducing potentials for violent conflict and terrorism when it contributes to the availability and awareness of life chances for a desirable future of people in the target countries. Development policy in the context of crisis prevention should therefore aim for:

- the establishment of democratic, transparent and participatory political systems;

- overcoming (structural and acute) poverty and fostering sustainable, socially and ecologically reconcilable economic development.

As a result of the new emphasis on crisis prevention for development aid policy the title Food Security was reframed as Food Security in the context of Crises, Conflicts and Catastrophes.

Food security and crisis prevention and conflict transformation are explicitly understood as interdependent and equally important development goals. Hence, food security programmes are implemented as part of a crisis, conflict or catastrophe preventive strategy.

The justification for this approach rests upon four basic assumptions with regard to food security, conflict, stability and sustainable development:

1. Stability and food security are the basis for sustainable development.

2. Food security and stability reinforce each other.

3. Stability and food security are fostered by four sets of development activities aiming at (a) availability of, access to and utilisation of food, (b) rehabilitation of essential infrastructure, (c) provision of conditions for

\footnotetext{
${ }^{2}$ For explanation of concepts and terms used see "buzzwords", appendix 7-26

${ }^{3}$ Bundesregierung 1998: 84

${ }^{4} \mathrm{BMZ}$ 07.04.2000

${ }^{5}$ Summed up from BMZ 18.12.2001: 2
} 
structural long term stability, and (d) strengthening conflict transformative competencies of groups and institutions. Point (c) is seen as targeting the structural causes of conflict while (d) is focused on strengthening constructive conflict processing. (See text box causes and dynamics of conflict on page 12)

4. Development measures targeting food security, rehabilitating infrastructure and strengthening structural stability can have and, indeed, should have a positive impact on conflict transformation competencies of target groups and institutions.

\subsection{Food security, regional co-operation and stability in the programme region}

The Food Security, Regional Co-operation and Stability Programme implemented by GTZ and its partners AKF and AKDN in Southern Kyrgyzstan, parts of Tajikistan and Northern Afghanistan is, together with a similar programme in the South Caucasus, a pioneering attempt to build on the assumed interdependence between enhanced food security and reduced risk of crisis and conflict.

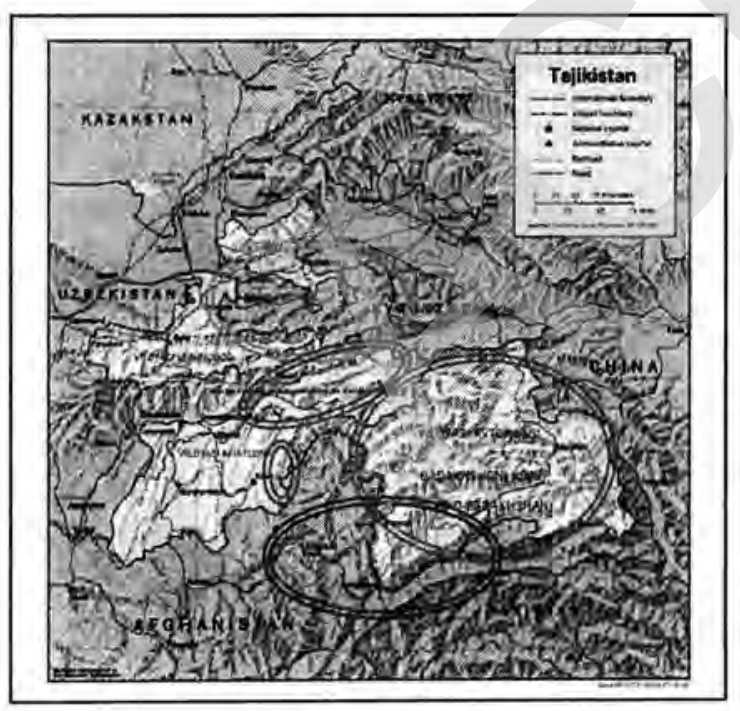

The programme consists of three independent projects with a similar design and shared objectives. The Kyrgyz project (blue circle) is implemented by GTZ in the southern administrative region (oblast) of Batken, bordering the Tajik mountainous part of the Rasht valley to the south and Tajik and Uzbek parts of the Ferghana valley to the west and north. The Tajik project (green circles) is implemented by MSDSP of AKF in the Rasht valley, bordering Kyrgyzstan to the north and the Autonomous Region of Gorno Badakhshan (GBAO) to the east; in GBAO, bordering Afghanistan in the south, China in the east and Kyrgyzstan in the north; and in Shurabad district, bordering Afghanistan to the south and GBAO to the east. In Afghanistan (red circle) AKDN is implementing the project for GTZ in Afghan Badakhshan province, bordering Khatlon province and GBAO of Tajikistan to the north. 
The three projects share the same objectives:

(1) To boost agricultural production

(2) To improve access to markets and develop small and/or medium enterprises

(3) To rehabilitate infrastructure

(4) To foster participatory co-operation of state and civil society actors in the local reform and state-building processes

(5) To strengthen the conflict transformational capacities of local state and civil society institutions.

In accordance with the strategic assumptions outlined above, objectives 1-4 are regarded as directly contributing to objective 5 .

The Tajik project, geographically connecting the projects in northern Afghanistan and southern Kyrgyzstan, has an additional objective (6), namely enhancing regional co-operation and stability.

The target regions and objectives of the programme were identified in 2001 due to perceived Islamist incursions from Afghanistan via Tajikistan into Kyrgyzstan and Uzbekistan (IMU incursions in 1999 and 2000) and before the unexpected and rapid fall of the Taliban regime in Afghanistan in autumn 2001. The target regions chosen for the programme coincide with the path the fighters of the IMU took during those incursions. At the time, the plausible fear was that incursions into vulnerable and remote areas of Tajikistan and Kyrgyzstan by Afghanistan backed groups may lead to the proliferation of weapons, drugs and, most importantly, Islamist ideology and terrorism. At that time, there was a risk of further amplification of local instability in Tajikistan, of a spillover of instability from Tajikistan into Kyrgyzstan, and of rising tensions between Uzbekistan, Kyrgyzstan and Tajikistan. ${ }^{6}$

The situation has, however, significantly changed since then. The remnants of the Taliban and their allies are no acute threat to the stability of Afghanistan's northern neighbours anymore. The peace accord in Tajikistan, however flawed by informal manipulation, holds and is not contested. The relationship between Uzbekistan and its neighbours remains politically tense though not for security reasons but because of the incompatibility of the different politico-economic regimes, with Kyrgyzstan a member of the WTO and Uzbekistan relying on a version of subsidised state-run economy.

Therefore, it seems appropriate to call for a reassessment of the selection of program regions and strategies.

\footnotetext{
${ }^{6}$ Bundesregierung 18.03.2002; BMZ 18.12.2001; Fastenau 20.06.2002
} 


\subsection{Objective of the report}

The objective of this report is to present in condensed form the results of the missions to Afghanistan, Tajikistan an Kyrgyzstan:

Firstly, we will explain the methodology used to assess peace and conflict potentials of the target areas on the local level. Secondly, we will present the results of the reports on the target regions in Afghanistan, Kyrgyzstan and Tajikistan and assess their relevancy for food security and conflict transformation. Thirdly, we will give recommendations with regard to the regional strategy of the programme.

There are three caveats:

First, this paper does not analyse macro-conflicts on a national or interstate level. Some excellent studies done with this perspective on conflict have already been conducted. ${ }^{7}$ Second, it was not an objective of this study to conduct a Peace and Conflict Impact Assessment: we are not analysing the impact of GTZ interventions and the implementing partners. However, recommendations are given on when, where and how elements of PCIA should be implemented. Third, the results of the empirical qualitative research are by default confined to the research locations and cannot automatically be transferred to a more general (national or macro-regional) level.

A comparison to the results of a similar study on the Caucasus food security and conflict transformation project may, however, help adapt overall strategies, refine the hypothesis on programme impact on conflict transformation and crisis prevention, and help to develop medium range indicators to assess this impact.

${ }^{7}$ Grävingholt 22.03.2003; ICG 2001, March; ICG 2001, November a; ICG 2001, November b; ICG 29.09.2003 Glatzer 2003, Freizer, Abdullaev 2003 


\section{Concept and methodology}

As has been mentioned before, sustained development is conditioned by three interdependent capacities of society. The first two conditions are of general importance, the third is of particular urgency in societies marked by unusual rapid change of the economic, political and cultural framework: (1) the capacity to process conflict in a non-violent and predictable way, (2) the capacity to secure the basic needs of relevant parts of the population, and (3) the ability to adapt existing institutions, norms and habits to new realities. ${ }^{8}$

Military occupation, as in parts of Afghanistan, is an extreme example of change imposed from the outside; economic collapse, institutional breakdown and Civil War in Tajikistan are other extreme examples of rapid change induced, to a greater extent, by internal dynamics. Both cases test society's capacity to adapt and reinvent itself to the limit. In this context conflict can be used as a heuristic tool to understand development opportunities and blockades. In other words, analysing the way society deals with conflict and crisis informs us about the strengths and weaknesses of target groups in producing adaptive change (i.e. development). Conflict analysis therefore does not only inform us about the conflict itself; it also informs us about the capacity of the social units of analysis (be it local state institutions at district or regional level, rural village communities or other defined target groups) to apply and, if necessary, adapt their norms and rules under the stress of changing and competitive environments.

\subsection{Conflict}

"Conflict means the struggle over values and claims to scarce status, power and resources in which the aims of the opponents are to neutralise, injure or eliminate their rivals". ${ }^{9}$ This classic definition, though some 50 years old now, still holds. It grasps the full range of what social conflict is about and what forms it may take (from non-violent competition to violent destruction).

From a development perspective conflict itself is not always the problem. Socially embedded conflict (that is, conflicts that are dealt with according to accepted and practised rules in a non-violent way) may be good for development, because it fosters adaptive change in a predictable and non-violent way.

\footnotetext{
${ }^{8}$ We should be aware, though, that these capacities are never fully available. In real life no society provides for guaranteed non-violence and guaranteed security of basic needs for all members at all times. Strong states functioning according to the rule of law appear to be more helpful than other political frameworks in getting closer to these ideal conditions. But even under the most favourable conditions, violence and insecurity remain part of the human condition. What forms and levels of violence are acceptable to society varies between and within societies and their sub-cultures. The same holds for what needs are seen as "basic" aside from the most obvious preconditions to biological and social reproduction.

${ }^{9}$ Coser 1956
} 
Such an understanding of conflict today is shared by a number of authors (e.g. Goodhand, Atkinson 2001; Grävingholt 22.03.2003; Barron et al. September 2003).

Most authors theoretically accept that good conflict is a necessary motor for change and therefore even a prerequisite for development. This concept is, however, rarely utilised in recommendations for programming, implementation and assessing development initiatives working on conflict.

Good conflict in this sense is institutionalised conflict. Societies have specialised institutions and procedures to process conflict in a predictable and non-violent way, These institutions may be formal (e.g. courts, parliaments, elections) or informal (e.g. courts of mediators/elders; markets/ bazaars; rules of co-optation, i.e. "buying" contenders and competitors with privileges; institutionalised forms of corruption).

Institutionalised conflict is not only necessary for a continuous readjustment of the balance of power within a group but is also essential for innovation and adaptation of structures and norms within society. Institutionalised conflict often is the driving force behind the order that keeps communities together. The acceptance and legitimacy of the local social order (from local governance and arrangements of water distribution to rules of marriage and religious practice) are significantly based on reliable and non-violent, non-disruptive processing of day-to-day conflicts. In other words the accepted way in which society deals with conflict is a defining characteristic of a society.

From a development perspective, bad conflict is the problem. Bad conflict comes in two varieties:

1. Conflict is bad when it is violent or likely to become violent.

2. Conflict is also bad for development when it leads to a disruption of intergroup co-operation, thereby blocking development opportunities. Such disruptive conflict may not necessarily be violent, but it should nevertheless be included as a target for development programmes aiming at working on conflict.

Thus, it is not conflict that should be the primary concern for development and aid initiatives but instead, whether conflict leads to violence, and whether the conflict leads to (non-violent) disruption in inter-group co-ordination because target groups choose to withdraw.

Community-centred development has the potential to "working with society where it stands", taking into account existing, socially embedded conflict processing mechanisms. Utilising such mechanisms in development strategies is, however, only possible if they do not contradict or compete with the efforts of state building. Local institutions that challenge the core functions of statehood have to be excluded from development co-operation (those core functions are: the monopoly of violence, the exclusive right to set the rule of law, and the unchallenged privilege to extract taxes 
in exchange for the provision of public goods). Customary law that includes capital punishment cannot be "worked with" by community centred development - no matter how effective it might be in locally processing conflict.

Thus, a central aim of conflict analysis that is of practical use to development and aid programmes is to identify which local procedures and institutions successfully deal with conflicts and should be strengthened and how they can be strengthened. This is the rationale for choosing the local perspective as a starting point for this study.

\subsection{Methodology}

We conducted qualitative field research in 7 districts in Afghan Badakhshan, 4 districts in Batken (Kyrgyzstan) and in three regions of Tajikistan (Rasht valley, Shurabad and Badakhshan GBAO) covering a total of 7 districts.

The fieldwork lasted for a period of 1.5 months in Afghanistan, 1.5 months in Tajikistan and 2.5 months in Kyrgyzstan.

In Kyrgyzstan and Tajikistan the unit of qualitative fieldwork coincided with the smallest level of local administration - the Ail Okmoter and Jamoat respectively. In Afghanistan we chose the informal traditional pattern of village clusters called Manteqa. All units of analysis provided a sample with comparable numbers of residents: not more than 15,000 and not less than 1,000 population.

\section{Causes and dynamics of conflict}

Conflict resolution. Some conflicts have clearly identifiable causes which can be targeted and eliminated. For example, when conflict is caused by unchecked competition between groups over a naturally scarce resource, it may be sufficient to increase the amount of the resource at stake.

If scarcity is the result of organisational problems, the case is more complicated: conflicts because of poorly managed and badly distributed resources require enhancing resource management and the organisation of distribution rather than making more recourses available to solve the conflict.

Other conflicts are multi-causal and multidimensional. Under such circumstances "[...] 'solving conflicts' does not so much mean eliminating their sources than the creation of functional political and social institutions that are capable of preventing the clash of interests to escalate into open confrontation" (Nodia, Bairamov, Sulemanova 2003: 84). Here another approach is required; an approach often referred to as conflict transformation in development-speak.

Dynamics of conflict. No matter what the causes of conflict might be, conflicts - and violent conflicts in particular - follow their own rules and develop dynamics that may be independent from the original causes of conflict. This is why the institutional capacity of communities to process conflict (that may emerge for whatever reasons) in a reliable, predictable and non-violent way is so important in assessing (and strengthening) constructive conflict management in and between local communities.

Conflict transformation refers to development interventions that aim actively at changing the way conflict is conducted in or between given target groups (communities, identity groups). The aim is to discourage destructive and violent or disruptive enactment of conflict and foster constructive, non-violent forms of conflict processing. The approach is broader than conflict resolution - implying that conflict is bad per se and has to be resolved for development to bear fruit - and conflict management - implying containment of bad conflict. Conflict transformation by contrast understands conflict as a social process in its own right which in itself is neither good nor bad. The way communities, the state or society at large deal with conflict may be destructive, constructive or neutral for development goals. Therefore, the concept of conflict transformation is process orientated rather than cause orientated. A critical asset of conflict transformation is procedures that change (uncompromising) either-or conflicts to (compromising) more or less conflicts. 
With the research we aimed to: (1) gather background information from a local perspective on causes and processes of conflict in the target regions; (2) assess the relevancy of local conflict and peace potentials for the objectives of the food security and conflict transformation project implemented on behalf of GTZ; (3) assess the implications of local conflict and peace potentials for regional stability and interregional co-operation within the programme area; (4) build capacities for GTZ implementation partners in order to independently conduct peace and conflict analysis.

The fieldwork was conducted by local research teams under the guidance of international consultants with a sound knowledge of the region and training in social research. Before going into the field the local research teams received five to seven days of training on key concepts, tools and research methods

In Tajikistan, the local research team consisted of MSDSP staff. MSDSP is a project of AKF and implementing partner for GTZ. In Kyrgyzstan, the local team consisted of GTZ staff and the newly employed staff of FTI, a local partner NGO to GTZ.

This approach ensured a high level of ownership and capacity building through learning and training on the job. However,. such an approach also posed the following constraints: (a) the selection of researchers was beyond the control of the team leader; (b) the researchers had multiple obligations and a bias towards the interests of their own organisation could not be excluded; and (c) the international fieldwork consultants were not charged with the authority to sanction poor effort or bad work by replacing researchers.

In Afghanistan, researchers were hired especially for this mission and paid directly by GTZ. The local implementation partner of GTZ (AKDN) involved the team leader and the fieldwork consultant in the selection of researchers. Decisions on sanctioning poor performance were taken jointly. The most promising researchers were either employed by AKDN afterwards or received follow-up research assignments. Retrospectively, from the point of view of research quality, the approach chosen in Afghanistan appears to be preferable.

\subsubsection{Why local analysis of conflict and peace potentials?}

While most conflict monitoring and early warning systems target the international and national level and rely on macro-indicators for analysis and prognosis, this research focuses on conflicts taking place at the community level or - if larger in scale - impacting on the local level. There are three reasons for this choice:

1. The presence of macro-risk factors does not inform us about how communities actually cope with those risks. Escalation of violence or nonviolent conflict processing depends to a significant extent on the institutional capacities of society to deal with stress and risks on the ground.

2. The scope of action of the GTZ food security programme in the region is the community level. The capacities of local society to come to terms with 
conflict as daily routine or as extraordinary event is, however, a terra incognita for donors and implementation partners alike. This is why a systematic peace and conflict assessment that is of practical value to the programme has to take the local perspective, working bottom-up rather than top-down.

3. Central state actors are beyond the reach of the tools available to the organisations implementing the programme or are at least not targets of the projects implemented. Regional co-operation between neighbouring countries on conflict and crisis prevention is usually the realm of the central state. However, when central states are unwilling (Uzbekistan) or not capable (Afghanistan, partly Tajikistan) of macro-regional co-operation, it may be an option to explore opportunities for regional co-operation between local actors. Some of the conflicts identified in our study are caused or fuelled by the past or present policies of national states but have an impact on stability first and foremost in the target regions (e.g. enclaves and border regimes in Batken oblast). Other problems are locally rooted and have at the same time strong cross-border implications for regional stability (e.g. poppy cultivation).

\subsubsection{Preference to qualitative methods}

The methods applied derive from social anthropological research and from rapid rural appraisal (in its adaptation to conflict research for development and aid practice). Both approaches focus on qualitative data and require prolonged fieldwork. The reasons for choosing this methodological approach for the current task at this pioneering stage of analysis are:

- The way communities deal with and talk about conflict is usually a sensitive issue. It is often concealed behind normative facades that reflect how the interlocutor imagines things should be rather than how they really are. Trust-building with key informants, cross-checking information and participant observation of social practice help to differentiate norm from deed.

- Not only normative (mis-) representation is a problem when trying to analyse the social practice of conflict. Also, the perception people have of conflict cannot be taken at face value for analytical purpose. This is not to say that the local perceptions are wrong and the outside perception is right or that perceptions of conflict are not important for conflict analysis. It is to say, however, that perception of a social process (like conflict) should not be confused with the process itself. Perceptions can be assessed in questionnaires; the politics of conflict - i.e. the unwritten rules, constraints and tricks according to which actors "do" conflict - can only be grasped by qualitative in-depth research. 
- While qualitative and participatory methods are useful for accessing local knowledge the research team has to be aware of the problem of the local population being blind to the significance of daily routine they consider self-evident. Teaming up informed outsiders with methodologically trained local researchers significantly reduces this risk of missing the obvious.

- Last but not least, in-depth qualitative knowledge is a precondition for developing smart, small and medium range indicators that can be observed and measured with quantitative methods at a later stage. The ideal research strategy is obviously a mixed method approach in which key results of qualitative research are tested against quantitative surveys. ${ }^{10}$ However, a comprehensive mixed method approach to conflict research was beyond the time frame of this research.

\subsubsection{Structuring the research and analysis}

In order to structure the analysis the research teams were provided with two tools:

(1) a selection of conflict arenas (clusters of similar conflicts) and (2) pre-defined crosscutting research categories of general importance to conflict processing.

We then compiled the collected data in a table that contained the conflict arena and the crosscutting categories. We refer to this table as the "matrix" (see appendix 737).

Conflict arenas are clusters of conflicts categorised by shared dominant features. Examples of conflict clusters are conflicts about:

- access to and distribution of natural resources

- conflicts related to border issues and border regimes

- conflicts arising around social differences (e.g. gender, generation. identity).

The clusters were developed in a participatory manner during the initial training and adjusted empirically during fieldwork. For the initial identification of most relevant conflict arenas a broad participation of local and international professionals working in the region was of great help. Locals may tend to neglect what they may either find self-evident (like power-relations between the generations) or taboo (like tension from rising gender awareness). Outsiders might miss less obvious tensions - like hidden cracks within governing elites.

\footnotetext{
${ }^{10}$ For a current example of mixed method research on community driven development programmes on conflict and peace potentials in Indonesia see Barron et al. September 2003; the time schedule for this research, focussing on just one province in one country, is 2 years.
} 
After having identified the tentative conflict arenas in the kick-off workshop, the research locations for the fieldwork were selected. The criteria for selecting the locations were (a) the number of conflict clusters relevant in one place and (b) the expected or known intensity of conflicts. Additionally, obvious questions of accessibility, security and inclusion in target areas of GTZ were considered.

Keeping the list of conflict arenas open during fieldwork proved to be important. Some conflict clusters which locals and international consultants expected to be of crucial importance during the initial training were dropped completely on the basis of empirical evidence - like the issue of informal tax collection by commanders in Afghan Badakhshan. Other arenas were discovered to be relevant only during the fieldwork - like rising gender consciousness among young women in the urban centre of Afghan Badakhshan.

While the identification of conflict arenas was a flexible process, six pre-set crosscutting categories were introduced to research conflict and peace potentials within each identified arena. They are (1) resources, (2) networks, (3) informal local institutions, (4) formal non-state institutions, (5) local state capacities and (6) social control (see textbox). The benefit of such an analytical grid is to have a shared research agenda focussing on resources and organisational capacities that are highly relevant for conflict processing but that are at the same time applicable to research in absence of overt conflict escalation. The problem we found with the methods that were designed for development aid organisations to

\section{Crosscutting research issues}

Resources are material and immaterial means actors may acquire and use in order to progress their interests and secure their needs. Examples for material resources are money, weapons, land, water, and fertilizer. Examples for immaterial resources are information, education, and prestige.

Conflicts may take place over the control of certain key resources. The identification of what is a key resource in a given community/society can only be understood from within the community. Different societies assign different meaning to resources. The relevancy of certain resources depends on the economic, political and cultural system in place.

Not only are resources an important object of conflict. They are also an important means of conflict. The ability to mobilise resources is of particular important in sustained violent conflicts.

A network is the structure of regular interaction between a larger number of individual or collective actors. A network in itself is not an actor and not an institution. It is not the same as those participating in it and it is not the same as the rules governing the interaction between the participants. A network can be used by the participants/actors to organise collective action. It is like a telephone network that can be used just to chat, to organise support, exchange information or organise a demonstration.

To determine the significance of a network in conflicts it is important to identify the social basis of the network that supports its cohesion and sets the rules of interaction. A network based on kin-relations may be more persistent than a network based on shared interests or on patron-client relations based on work-history.

Institutions are the rules of the game in society. In other words they are the constraints shaping the interaction between collective or individual actors. Institutions are mechanisms in society that guide actors by setting the rules for interaction, exchange and relationships between individuals and groups.

Formal or official institutions are usually constituted in writing and protected/implemented by the state. Informal institutions are constituted by routine, tradition, upbringing, habit or custom and protected by social control, often exercised by informal authorities. Official institutions and informal institutions can be intimately linked: a court, a body of local self government, an election may all at the same time work according to official and unofficial rules. For the analysis of conflict it is important to examine whether informal and official institutions contradict each other, compete with each other or support each other. It is also important to determine which set of 
assess conflict - like stake holder analysis, conflict profile, time-line, conflict mapping - was that they work well only when parties to the conflict, stated positions of actors to the conflict and interests pursued in conflict are explicit. These tools are not designed to analyse latent conflict or subtle social tensions. For the time being, however, in the target region of the GTZ programme violent conflict is more the exception than the rule. At the same time tensions hidden from the public eye are high, constructive conflict processing is often blocked by the organisational weaknesses of local state structures, and informal social institutions are unable to fill this gap and reliably process conflicts. In addition to the identification of structural sources of such instability, the crucial question is how efficient local arrangements of governance - often hybrids of official and informal institutions that "work" in the absence of effective statehood and civil society are in terms of conflict control. Do they facilitate conflict transformation or just temporarily contain conflict by blocking mobilisation and development? In rules is dominant. In some cases an official body - like a local state administration - may only have an official façade and work mainly according to informal rules.

Communities usually have mechanisms in place that punish deviation and encourage conformity with existing rules. If these mechanisms are not enforced by official state bodies we call them social control. Social control can be used for mobilisation of collective action (e.g. hashar, demonstrations, or attack on a neighbouring community). It can also be used to check mobilisation (controlling the hot-heads in a conflict, controlling the access of young men to weapons...). Social control can be either social capital or a powerful infringement for development and adaptive change.

For the analysis of conflict the scale of social control is important, the sanction capacity of social control is important and last not least the rules of control are important.

State capacities are defined as the capacity of the state to provide public goods such as social security, physical security and rule of law. A public good is characterised by nonexcludability (everybody within the constituency can consume the good, even if he has not contributed to the production / financing of the good) and by non-competition in consumption (the consumption of the common good by an individual does not reduce its worth for another individual). Social security, physical security and rule of law are vital preconditions for stability. For the analysis of conflict it is important to see how much of these public goods are provided by the state. If the state does not provide these public goods it is important to know whether there are alternative providers.

essence, the matrix proved to be an analytical tool to account for peace and conflict potentials within such local modes of governance.

Last but not least the matrix helped consolidate the conflict and peace potential analysis with the GTZ programme objectives. Analysing the different conflict arenas according to the crosscutting categories sheds light on what problems should be targeted with the tools available within the sectors of activity of the GTZ food security programme (agriculture, organisation development, infrastructure, SME) in order to foster conflict transformation. A number of our case studies show that a crucial question is whether enhancing the organisational capacities of distributive agencies have to precede technical or material assístance to yield positive results with regard to conflict transformation. 


\section{Conflict Arenas and Conflict Transformation in the Target Areas of Afghanistan, Kyrgyzstan and Tajikistan}

\subsection{Country context}

\subsubsection{Afghanistan}

The province of Afghan Badakhshan has suffered some twenty years of war. Following the Russian occupation and withdrawal, a number of Mujahedin parties and factions have established themselves in the province. Most prominent among them were the Shura-i Nazar, the faction of the late Ahmed Shah Massoud, the mainstream Jamiat-e Islami, still under the control of Burhanuddin Rabbani and some pockets of Hezb-e Islami, the party of the now wanted warlord, Gulbuddin Hekmatyar. In the last years of the Afghan Civil War the province became the last main supply route of the anti-Taliban Northern Alliance. Despite repeated efforts, the Taliban never managed to take Badakhshan.

The current political set-up in the province is highly complex. Since the fall of the Taliban regime and the installation of the Afghan Transitional Administration under President Hamid Karzai, the political and military situation is gradually getting more stable. Increasingly the state seems to emerge as a key player in Badakhshan's political arena. However, the state does not yet in any way hold a real monopoly of violence. Even though some two thirds of the province is wholly and another $10-15 \%$ partly under state control (with only $10-15 \%$ remaining fully outside the influence of the state), much of this control rests on an uneasy alliance with local commanders and with the backing of the international community. Locally, political power frequently still lies with commanders who tend to be associated with a politicalmilitary party. The gradually expanding influence creates a lot of unease with these commanders, many of whom fear to loosing their position of power and prominence.

This fragile mixture of conflict and co-operation between the state and commanders is further exacerbated by remnants of the war economy and the still expanding poppy economy. Even though poppy cultivation has a long tradition in Badakhshan, it has only really started to expand since 2000 through a peculiar mixture of circumstances: a three-year long drought and the Taliban ban on poppy cultivation in 2001. The drought created the need for farmers to explore new ways of earning a living (a push factor). The massive hike in opium prices following the Taliban ban made opium the economic alternative of choice in the only province outside Taliban control and thus not affected by the ban (a pull factor). Currently Badakhshan is the third largest opium-producing province in Afghanistan. The opium economy is rapidly leading to far-reaching socio-cultural changes in rural Badakhshan. It is, however, not just the countryside that is affected by the ban. The enormous profits 
on higher levels of the drug trade, threaten to corrupt state officials and thus to undermine still weak state capacities.

Partly also due its crucial role in the drug trade, Badakhshan is receiving increasing attention from the international community. In 2002 there was a brief attempt by the British Army to eradicate the opium crop by paying compensation to farmers that cultivated poppy. This attempt is generally believed to have failed, as the significant compensation is even said to have motivated some farmers to intensify their production. Moreover, it did not lead to any meaningful drop in opium output. With the compensation strategy having been abandoned, the first serious attempt at poppy eradication and drug trade interdiction might be expected this year. Indeed, a heroin factory in Faisabad was reportedly raided in February 2004 by internationally trained Afghan anti-drug police. Despite increasing international attention being paid to the Afghan drug trade (and its potentially grave consequences with regard to state building as well as the financing of terrorist groups such as the Taliban and $\mathrm{Al}$ Qaida), the recently deployed German peacekeeping contingent in north-eastern Afghanistan is unlikely to get directly involved in the problem. Its presence might nevertheless provide the necessary stability for anti-drug, police action to take place.

\subsubsection{Tajikistan}

Since the end of the Civil War (in 1996) there has been slow progress towards more stability in Tajikistan. The consolidation of central authority is progressing, as the President is building up his network, and potential opponents are co-opted or excluded. However, this process of strengthening central authority by investing in networks of patronage should not be confused with the strengthening of statehood. Statehood in the sense of working impersonal bureaucratic institutions is still extremely weak.

The tensions between those regions that sided with the government during Civil War and the so called opposition regions are easing, although mistrust and above all an almost complete lack of information about the Other remain. The situation in the former opposition region of the Rasht valley is slowly improving. Central authorities are gradually taking over control from former "local strong men". Armed militias do not play a prominent role any more, although the process of disarmament is far from complete and there is still a small weapons problem.

There is also slow progress with regard to the material situation of the population, mainly due to international donor activities. Finally, since 2001, the situation in Afghanistan has improved. Tajikistan has a $1300 \mathrm{~km}$ border with Afghanistan, and was and still is very vulnerable to spillovers such as drug trafficking and the export of arms, fighters or ideologies. The regime change in Afghanistan and the strengthening of the border with Afghanistan (mainly due to Russian border guards) have improved the security situation. 
Despite this progress, the country is still far from having achieved structural and sustainable stability. Tajikistan has the poorest resource-base and the weakest infrastructure of the Central Asian states and has suffered the sharpest economic decline. Among the risk factors that currently affect stability in the country are: the deeply entrenched regionalism; the omnipresent patron-client networks (which are often based on regional origins); the dire socio-economic constellation; the threat of Islamic unrest; the high dependence on income from labour migration, drug money and international donor money; a growing inequality of access to land; and most importantly, the threat of a break down of the elite coalition that form the core of President Rakhmonov's rule.

\subsubsection{Kyrgyzstan}

Compared to the problems facing Afghanistan or Tajikistan, Kyrgyzstan can be described as a functioning state with significant organisational deficits. Until recently it was widely considered a show case democracy among more or less authoritarian regimes in the rest of Central Asia. While endemic corruption and a worsening human rights record, particularly with regard to the treatment of sections of the political opposition, has tarnished this image of late, the state is stable and unchallenged. Kyrgyzstan is the only WTO member in Central Asia with a market economy in place that is free of overt state intervention (baring in mind the mentioned corruption of officials). It is probably the only Central Asian country in which modest social welfare in practice reaches even remote regions like the target region of Batken oblast.

Batken oblast in southern Kyrgyzstan is part of the Ferghana valley in Central Asia. In the 1990s, the valley became notorious for a range of political, economic and social problems, resulting from the break-up of the Soviet Union. In the last decade, parts of the valley, especially in Uzbekistan, attracted international attention. The incursion of several hundred fighters of the Islamic Movement of Uzbekistan into Batken region in 1999 and again in 2000, focused international attention on this peripheral part of the Ferghana region.

The Kyrgyz Government reacted to both the new threat and the potential for development programmes which international awareness brought the region, by upgrading the region to an independent administrational unit, i.e. Batken oblast. The impoverished region since has been portrayed as a potential breeding ground for militant Islamism.

With the attacks of 11 September 2001 and the shift of international interest to Central Asia, the international community has increasingly developed programmes and projects to combat the economic decline and social tensions in the Batken region. Most of these activities aim at the prevention of conflict escalations.

Since the fall of the Taliban government in Afghanistan and the stabilisation of central control in Tajikistan the risk of a spillover of armed conflict, and of 
proliferation of arms, drugs and radical ideology, ceased to be critical problems, Today the most pressing problems of the region are related to: complex border regimes; the unfinished and disputed demarcation process around a multitude of enclaves of neighbouring countries within Batken oblast; competition over key natural resources like water and arable land between different communities; and conflicts arising from the poor institutional capacities of local state and civil society with regard to the management of those problems.

\subsection{Political arenas}

\subsubsection{Arena: Local modes of governance}

Local governance refers to the way political and economic power is organised at the local level and how this organisation of power affects society. Hybrid arrangements between official local government ${ }^{11}$, official state and non-state bodies of selfgovernment ${ }^{12}$ and informal power holders ("big men") ${ }^{13}$ were found to have a strong impact on the occurrence and processing of conflicts in all regions. Particularly in the regions marked by weak central state control those modes of local governance are paramount in determining the prospects for conflict transformation.

\section{The problem}

Afghanistan: local governance without state or within a contested state

Based on the case studies from Afghanistan we find that violent ways of conflict processing are on the decline in those districts where the new state administration (woliswolli) is well established and unchallenged in setting the rules of local governance. This finding is a remarkable one given the fact that even in those comparatively better - administered districts the state is far from having an uncontested monopoly on violence, and that there is an almost complete lack of infrastructure for effective governance such as communications, technical hardware, cars, offices etc.

By contrast, local governance is conflict prone when official state rule is either absent or when local governance is contested between new state actors and established informal potentates ("local big men"). Both settings occur in Afghan Badakhshan, where state-building is taking place from scratch. For example, we found that the arbitrary rule of renegade commander Kariwadood in the border district of Ghuaran aggravates and at times leads to violent escalation a range of existing "ordinary" conflicts that elsewhere are processed peacefully. Also other

\footnotetext{
${ }^{11}$ Like the office of the rais (head) of the hokumat (local administration) in Tajikistan or the wolliswol of the wolliswolli in Afghanistan respectively.

${ }^{12}$ Like local councils; VOs; or NGO/NSP shuras.

${ }^{13}$ Like former commanders in the Civil War in Afghanistan or Tajikistan or local big men with significant social standing involved in legal or illegal business in Kyrgyzstan and Tajikistan.
} 
regions, to which state governance is only just trickling down, power relations are still unstable and often violent. Fights among commanders are mostly characteristic, but other contenders for local power may also get involved. ${ }^{14}$

Against the backdrop of often violent and arbitrary conflict processing, we find that in Afghan Badakhshan the demand for more state involvement in local governance is high and clearly exceeds the available supply.

Having said this, high expectations have to be cautioned. Even in those districts where the local state administration has (limited) capacities for conflict resolution there is still a long way to go until conflict processing is based on legal principles. For the time being the new administrators are forced to navigate through the waters of real power by virtue of mediation, negotiation and compromise. ${ }^{15}$ Their decisions are de facto no more binding than those taken by traditional bodies of mediation (shuras). However, the geographical scope of their decision-making competency is wider and usually comprises of the whole district whereas the decisions of traditional bodies of mediation are confined to the village. At present, agencies of local government have very few enforcement capacities, and consequently foul play is not punished. An additional serious problem is that decisions of both traditional mediators and agencies of local government can be "bought". Last but not least it is usually not the impersonal state bureaucracy (such as for example the court) that is committed to conflict processing but the local state administrator personally. Decision making and arbitrage is thus often personalised and for sale, even if it is exercised by formal state structures.

This set of problems of local governance with regard to conflict processing may be attributed to the infancy of state-building. Taking a look across the border into Tajikistan draws a less optimistic picture of a potential future for state-building gone wrong. It is a picture of sustainable bad local governance within a sustained weak state.

\section{Tajikistan: bad local governance within an uncontested state}

In today's Tajikistan the attempts of the central state to establish its rule in the districts are no longer openly and/or violently contested. This refers to both the regions that sided with the government during the Civil War (such as Shurabad) and the so-called former opposition regions (such as GBAO and especially the Rasht valley). Thus, potential opposition to central rule is no longer problematic, so much as the characteristics of the central rule as it slowly trickles down and establishes itself in the districts.

Based on the findings of the case studies we identify two issues of relevance for both the political future of Tajikistan and for strategic programming of development

\footnotetext{
${ }^{14}$ Examples presented in the report are the cases of Khustak in Jerm district and Khandud in Wakhan district.

${ }^{15}$ See the interview with Jurm Walliswol on Khustak mediation in murder case, appendix 760
} 
and aid organisations. The first is the relationship between the "local big men" and the state; the second is the predominance of networks of patronage.

Stability and peace in Tajikistan (and, even more so, in Afghanistan) significantly depend on whether "local big men" are on the rise or on the run vis-à-vis the state. Both the emerging state in Afghanistan and the consolidating state in Tajikistan need to tackle this task, although the situations differ. In Afghanistan the local commandons appear to be more often feared and hated than former commanders are in Tajikistan. In Afghanistan the power of commandons still resides mainly with their capacity to organise effective violent action. In Tajikistan, former commanders quite often turned into "businessmen", border guard commanders or police officers, enjoying a high social standing ("they know how to live"; "they get things done"). Many have been co-opted into the influential networks of patronage, which often go hand in hand with receiving formal positions within state bureaucracies. However, both in Afghanistan and Tajikistan "local big men" still wield significant influence over scarce and/or disputed resources and often set and enforce their own rules to their own benefit.

Patronage is the key element of political power in Tajikistan. As resources and positions are distributed mainly within patronage networks, the importance of the network is strengthened, while the importance of state institutions is weakened. Cooptation into the network seems to be the key strategy of the president for checking possible opposition forces. At least in the short run this strategy seems to be working rather well. Co-opting players from former opposition or from regions other than the presidents regions into the ruling network is a way of stabilising the postconflict situation. Central authority in the districts is thus exercised not by the rules of official state administration but rather via vertical patron-client networks. In the research sample we identify three different strategies of local control via patronage: (1) direct presidential patronage in Shurabad district; (2) indirect patronage via an appointed governor (GBAO); (3) the patronage of powerful former opposition leaders that were co-opted into the central governing circle following the peace accord in 1997 (as the case with Minister of Emergency Situations and Civil Defence, Miro Ziyo, and his influence in the Rasht valley).

To sum up, local governance in Tajikistan as it is today poses three serious problems for peaceful sustainable development:

Firstly, the power of local official and informal players in de facto local governance depends chiefly on vertical patronage; consequently the loyalty of the beneficiaries of this patronage is with their patrons rather than with the best interest of the state. Local state agencies therefore do not provide neutral arbitrage, they offer no procedures for conflict processing nor do they have capacities to implement binding decisions in conflicts.

Secondly, since networks have hijacked state bureaucracies, the function of local state bodies is transformed to serve the network's interests rather than the public interest. For parties to a conflict, access to and protection by the right networks is more important than "having the law on one's side". 
Thirdly, the predominance of vertical networks of patronage ("vertical" because the networks depend on the patron in the centre) renders any attempts at horizontal inter-communal networking and coalition building a useless and futile endeavour. Local leaders see as their foremost constituency the patron and not the local population or local legislative bodies. This promotes the atomisation of society: the predominance of networks inhibits any incentive for balancing power locally by negotiation and striking compromises. In other words, it makes local politics superfluous. As a result, communities lack access to mechanisms of coming to terms with inter-communal and regional conflict issues, or with conflict vis-à-vis the political elite. Conflict processing capacities are thus strictly restrained to the scope of the village.

In conclusion, it may be argued that the Tajik scenario is an undesirable future scenario for Afghan Badakhshan. In Tajikistan, state-building is for the time being reduced to centralised network-building. Worrisome from an aid and development perspective is the fact that the absence of functional local governance seems to be quite sustainable - at least as long as the top patron, the President - is in command. An unfortunate consequence is, however, that the preconditions for sustainable development - food security, conflict transformation and rehabilitation of crucial infrastructure as public goods - are blocked by the system that is supposed to provide them in the first place.

\section{Kyrgyzstan: local governance in a weak but uncontested state}

The analysis of conflict and peace potentials in Batken oblast of Kyrgyzstan did not establish a clear link between the modes of local governance and conflict processing. However, we find that misuse of power, the organisational weaknesses of state agencies formally charged with conflict management and the impact of donor money and policies are three important problems directly related to local governance.

Prominent examples of the misuse of power are the many checkpoints on transit roads in border zones in Batken oblast. The issue of the checkpoints recently triggered demonstrations and led to tensions as approximately 300 people blocked an important transit road in Boz Adir (11.11.03). Both analysts and the local population have a hard time understanding the official rationale behind the number and locations of these checkpoints. It is a widely shared and substantiated assumption that the main incentives for having these check points relates chiefly to the informal income that can be generated for the members of the agencies that run them. There are also allegations that accuse the former (now ousted) governor of using check points to his personal advantage vis-à-vis the central government in Bishkek by causing controlled conflicts that he then could "resolve" and then earn credit from the public. ${ }^{16}$

\footnotetext{
${ }^{16}$ An allegedly secret police report, signed by the head of police of the oblast, accused the governor shortly before his removal of manipulating ethnic tension via checkpoints. The
} 
The second issue of relevance is the organisational weaknesses of important local state agencies. A case in point, which highlights the general problem, is the mismanagement of water. Access to and distribution of irrigation water is a crucial problem for a population that, since the break-up of the Soviet Union, is increasingly dependent on irrigation-intensive small-plot subsistence agriculture. Lately, uncoordinated community based-strategies for self-help are aggravating intercommunal conflicts (see "water" conflict arena below). The cause of the problem is, however, not a lack of water per se but the organisational weaknesses of the irrigation departments on district and regional (raion) level. These local state bodies are de jure responsible for organising and maintaining irrigation systems, for solving disputes and for implementing decisions that relate to irrigation and water use. On the operational level these state bodies are, however, all but defunct. They routinely issue mutually contradictory approvals of disputed water extraction projects and do not provide any meaningful procedures for decision making in disputed cases. Communities build their own "wild" irrigation canals or extract more water than has been allocated to them.

The third issue relates to NGOs and INGOs and is of general relevance for all three countries in which research was conducted. These organisations initiate resource transfers and policies which may become unintentionally important contributions to sub-optimal modes of local governance.

Until recently, communities in Batken were by and large left to strategies of self-help and muddling through. After the events of 11 September 2001, international attention began to focus on the region of Batken - the only region of Kyrgyzstan that had actually been affected by two Islamist incursions. Subsequently, aid and development projects quickly became a new patch in the patchwork of local governance. As a consequence, a tendency for local administrations to "outsource" difficult and expensive problems to various donors competing for meaningful projects has emerged. Such projects may ease pressure on local government, but (administrative) development blockades are indirectly reinforced. An alternative, potentially more promising approach, is presently being implemented at the national level on the initiative of the World Bank. This project sponsors the establishment of self-governing water user associations. Upon successful implementation, these associations then become the only accepted local partner institution by the district Irrigation Departments. This large-scale effort of boosting local ownership, selfpolicing and organisational capacity vis-à-vis badly functioning state institutions may create a strong lobby pushing for change within the system of local (bad) governance and mismanagement.

In the rural regions under scrutiny, donor resources are a very significant part of the local economy. Most often NGOs and INGOs are in fact the sole provider of public

report was readily made available to the team without motivation on his part, indicating that the report was part of the ongoing power struggle between the centrally appointed chief of police and centrally appointed governor. For the report see appendix 7-53 
goods on a community level and the dominant provider of non-agriculture incomes. This in itself makes donor activity a political activity. For donor strategies that target conflict transformation through the organisational development of local selfgovernance this point has to be stressed: such involvement is, for better or for worse, politically charged social engineering.

During the research we established four types of NGO involvement in local governance that are highly problematic for donor impact on conflict and development. Firstly, donors may be directly drawn into conflicts by conflicting parties either hijacking the project as a whole or significant assets of a project. This risk is particularly high with community driven development approaches in a context where the mode of local governance is marked by violence, force and fear. ${ }^{17}$ While it is more difficult for local big men do exert direct pressure on expatriate representatives of donor organisations they may have considerable leverage over local implementation partners, particularly when they reside in the community.

Secondly, donor activity may indirectly stabilise bad local regimes by tempering the negative effects of bad local governance with more active parts of the population and thus relieving the local power holders of popular pressure. Donor resources may subsidise such regimes by turning a blind eye to the diversion of supplied resources (including work places and salaried jobs in projects). Donor activity may also unwittingly contribute to the legitimising efforts of local regimes simply by allowing big men, commanders and corrupt administrators to take personal credit for public goods provided by development and aid organisations. ${ }^{18}$

Thirdly, in places where the local state government is too weak, too disinterested or too disorganised to set the rules for the delivery of public goods, long-term donor activity may end up substituting, replacing or competing with constitutional local government. Competition is most likely to occur in regions with extractable resources of interest to central elites. If those regions are not of interest to the elites they may even welcome such developments, outsourcing some of the state's core functions to NGOs. The sustainability of such arrangements depends, however, on resource inputs generated beyond the control of the national state and is contingent on donor logics of need - and publicity - assessments. International policing (the main job of intervention armies after invasion) and international development are, indeed, in danger of replacing two core functions that legitimate central statehood in the first place: the credible claim of enforcing a monopoly of violence and the delivery of human and economic security as public good. The problem is

\footnotetext{
${ }^{17}$ See for example the case studies on security commanders' involvement in the construction of the Khandud clinic in Wakhan, Afghan Badakhshan (Afghan Badakhshan report, p. 38ff) or the involvement of a car and driver belonging to a local Tajik partner NGO for tolerance development of a number of donors in smashing a border post on the Kyrgyz side (Batken report p. 98).

${ }^{18}$ An example of a local big man taking the credit for donor provided aid and services is Jan Mohamed in Khandud, Wakhan, in Afghan Badakhshan (Afghan Badakhshan report, p. 44). The strategy of local commanders to "pay off" people loyal to them by providing them with paid jobs in donor financed projects is outlined in the Ghuaran and Khustak case studies in Afghan Badakhshan (Afghan Badakhshan Report, p. 32ff; 48ff).
} 
sustainability. While the state presents itself as eternal, international intervention claims to be brief and working hard on making itself superfluous. In order to contribute to building a state that stays development organisations that go should very seriously avoid mimicking core functions of the state without involving the state. ${ }^{19}$

Fourthly, implementing development strategies without co-ordination with other significant development agencies may diminish effectiveness and may even neutralise achievements. Efforts of donors that compete to achieve the same results may encourage a donor shopping mentality on the side of (state and non-state) key players in local governance. Pressing for organisational and institutional change becomes much harder when donors are not co-ordinating their programmes on strategic goals regarding local governance. Parallel programmes evolve because of mutual ignorance between agencies on the ground and a lack of horizontal coordination. The transparency and accountability of projects is often institutionalised as an internal bottom-up obligation. Accountability in relation to local state and nonstate organisations that are affected by the programmes and horizontal transparency between donor organisations is rarely available. ${ }^{20}$ Organisational problems of donor activity are, indeed, also caused by a lack of the essential capacities of good governance that should be inbuilt in donor programme implementation. $^{21}$

We have outlined at some length the problems for food security and conflict transformation caused by different modes of local governance in the target regions. Local governance - effective or ineffective, state or hybrid - sets the institutional framework condition in which donors and their partners work. If the goal is, essentially, to enhance local availability, access and utilisation of crucial resources and the same time facilitate conflict transformation, local governance must be a key target of development strategies, namely because it is both part of the problem and part of the solution to the problem.

\section{Conflict transformation - measures available}

Firstly, with regard to conflict transformation, "ideal" local governance would provide or facilitate provision of:

- negotiated agreements between conflicting parties by accepted and well known, often written procedures;

\footnotetext{
${ }^{19}$ For the Afghan case of cicles of unsuccessful state-building attempts see Cramer, Goodhand 2002.

${ }^{20} \mathrm{Cf}$. Goodhand, Atkinson 2001 on the problem of downward accountability.

${ }^{21}$ An example of neutralising efforts from a lack of co-ordination between agencies targeting the same set of problems of a community is provided in the Aksay case study, Batken oblast, Kyrgyzstan (p. 43ff).
} 
- formalisation of the agreements and decisions into binding contracts;

- implementation of the agreements and decisions;

- monitoring so that parties stick to the contract and play by the rules;

- a credible sanction mechanism against foul play and parties breaking the rules;

- a policy of transparency with regard to the above mentioned mechanisms.

Local governance - good or bad - is always exercised by a multitude of actors such as local government, local self-government, informal power holders, civil society and international organisations. Therefore, not all of the above mentioned tasks have to or, indeed, should be provided by local government (official state bodies).

Provision of negotiations, procedures and monitoring of agreements can often be effectively done by civil society itself. On the other hand, formalisation of agreements and sanctioning of rule breaking is often done more efficiently by the state. Of importance is that this division of labour between state agencies, civil society or international organisations is done according to rules whatever the case. It must remain the prerogative of the state to set these rules.

A strategy that aims to strengthen local conflict transformation capacities should first and foremost detect institutions that actually or potentially provide procedures, formalisation, implementation, monitoring and sanction. These functions are crucial for peaceful and predictable conflict management in any community or society. Strengthening the provision of such functions within official organisations of local state and civil society means in fact strengthening legalism against arbitrary rule, against networking and against patronage. It is in itself a very meaningful contribution to conflict transformation.

Secondly, as with all other fields of interventions, the do-no-harm principle should also be applied to all interventions that affect or are affected by local governance. A meaningful do-no-harm check must account for four problems of unintentionally getting involved with local governance: (1) is there a risk that the project might get dragged into an existing conflict? (2) Is the project stabilising arrangements of local governance that are clearly bad for long-term development? (3) Are the initiatives replacing core local state functions in an institutional sense or are they competing with them? And (4) is donor competition and the lack of donor co-operation itself an example of bad governance and an arena for local conflict?

Based on a do-no-harm check, it would be possible to make a better informed decision about when it is time to get out and when it is better not to move in. 
Our analysis identified three conditions with regard to local governance that make development projects futile and infeasible. Firstly, areas that are completely out of state control and/or are governed by renegade commanders or criminal groups (like Ghuaran in Afghan Badakhshan and, possibly, Jirgatal in the Rasht valley in Tajikistan) require law enforcement prior to development. It should be noted that moving out of areas that become unbearable from a do-no-harm perspective requires close co-ordination with other development organisations. Otherwise the impact of such a move will be very limited.

Areas that are overrun by badly co-ordinated and competing donor initiatives (as shown in the Batken report, the Aksay case study in particular) should only be entered after careful preparation on the side of the donor and their implementing partners. Priority of investment in donor co-ordination and joint strategic planning, including the identification of lead agencies for certain sectors of local development initiatives, is essential. The analysis of tension and conflict with regard to water distribution issues in Batken oblast makes a strong argument for this point. For example, reorganisation and rehabilitation of the irrigation system would be more effective if an agreement could be reached among various donors that the World Bank, which is charged with developing a nation wide reform project, would be the lead agency in this sector.

Thirdly, it is desirable to expand the scope of existing good local governance. For example, Village Organisations in Tajikistan, Shuras in Afghanistan and Water Users Associations in Kyrgyzstan, are institutions that transform conflicts (conflicting interests, competition about resources and distributive offices, for example) within communities in a predictable and non-violent way on a day-to-day basis.

However, the drawback of these institutional arrangements is that they only work well on a community, i.e. village level. Here, in the village, the absence of the state as supreme watchdog can be substituted for by social control. It is the "eye" of the village $^{22}$ (that is, traditional institutions) that watches over decisions reached, negotiated contracts and compromises, monitors their implementation and sanctions foul play with social exclusion and the attribution of shame. Local governance in the kishlak (village community) works without the state. Such mechanisms seem to work well on village level in most parts of Afghan Badakhshan and Tajikistan. Beyond the kishlak, however, conflicts are either left in limbo or are decided by power rather than by legal principles and due procedures.

The crucial next step for development programmes focussing on conflict transformation is therefore finding a smart institutional connection of the village level to the district and regional level. The WB approach plans to connect Water User Associations (WUA) to the theoretically competent but de facto defunct Irrigation Departments of the district and rayon level. In Afghanistan, local state institutions are being built from scratch; thus far there is only a transitional administration to

\footnotetext{
${ }^{22}$ In prosaic terms the eye of the village refers to institutionalised gossip, rumours and character assassination at community level. It also refers to an often despotic absence of privacy in traditional societies.
} 
connect to. The case of Tajikistan appears to be most problematic. To put it bluntly: if the system of government that reaches the local level is intrinsically flawed, the great temptation for donors and partners is to built up an alternative, functional local administration from below. This may work where the central elite is utterly uninterested in preying on resources. It is, however, in any case not a desirable solution from the point of view of state building.

\subsubsection{Arena: Border related issues}

National and geographical borders at the same time connect and divide the research regions. Within the given research design we are interested in the impact borders have on conflict risks and conflict processing capacities of communities affected by borders both as physical infrastructure and in the institutional sense of border regimes.

\section{The problem}

Three sets of borders need to be distinguished in this analysis: The borders between Afghanistan and Tajikistan, the borders in the Ferghana valley between Tajikistan, Uzbekistan and Kyrgyzstan, and the borders between Tajikistan and Kyrgyzstan. Problems and opportunities widely vary, and there cannot be a single approach.

Firstly, there is the heavily guarded interstate border between Afghanistan and Tajikistan. This border has been closed since 1936, and contact between ethnic kin on both sides ${ }^{23}$ was blocked. However, in the period between Tajik state collapse in 1991 and the re-establishment of effective border control by Russian border guards in 1996, contacts across the river Pyanzh were intense, encompassing hosting of refugees on both sides; providing safe havens for armed groups under pressure in their respective countries of origin; arms and drug trafficking; and "ordinary" trade and family reunions.

The border regime today between Afghan Badakhshan and the Tajik target regions of GBAO and Shurabad along the Pyanzh River is characterised by what might be called "outsourced" national security. Since 1993 the border has been guarded by CIS border troops under Russian command. In 2000 the regime of control was tightened and illegal trespassing got much more dangerous. Freelance drug trafficking was significantly curbed. So were uncontrolled movements of refugees, traders or people seeking medical treatment in Tajik hospitals. This has, however, improved local security only partially. Criminal cross-border activities - drug trafficking and settling accounts between the groups involved - appear to be more

\footnotetext{
${ }^{23}$ Ethnic composition on both sides of the border resemble each other. It includes Tajiks, Kyrgyz and Pamiri groups.
} 
controlled now only in the sense that the business has got more professionalised and centralised. There are some serious indications that this trend was motivated by both the Tajik state and the Russian border command taking control of the business, not by establishing law and order but by "nationalising" it. Whatever the truth, the impact on local communities in terms of physical and social security is ambivalent: the free-to-all-who-wishes drug bonanza of the 1990s is over and consumption in the target regions (not in Dushanbe though!) has dropped significantly. Big drug business simply bypassed the local population, both in terms of negative effects like rising addiction but also in terms of revenues and investments from the illegal business. Those who still try to make a living by freelance trade risk their life and often lose it at the hands of Russian border guards "doing their duty". ${ }^{24}$ On the other hand in Shurabad the research suggests that a rise in heavy drug trafficking has deteriorated the security situation for many border villagers. Most tend not to leave their homes after dark for fear of becoming witness to illegal activity or getting caught up in drug traders settling accounts. Some villages have even been completely abandoned because of these security threats.

Other, less serious inter-communal cross-border conflicts involve allegations of illegal land acquisition by manipulating the flow of the border river and the illegal exploitation of scarce forest in the border zone (allegations made mostly on the Afghan side). Occasional shoot-outs have been reported, triggered by such resource competition. Theft of cattle and other property on the Tajik side by armed intruders from Afghanistan is usually related to the drug business when compensation is taken for supplies that were not paid for. The same appears to be true for occasional hostage taking.

There are also interstate borders in the Ferghana valley between Tajikistan, Kyrgyzstan and Uzbekistan. During Soviet times these borders were merely administrative borders of little relevance, except for the administrative de-facto control over the collective farms. Owing to the centralised organisation of the official Soviet planned economy the Ferghana region was not an integrated economic space from the point of view of official state enterprises. ${ }^{25}$ It was, however, integrated in terms of infrastructure like irrigation systems. It was also integrated from the point of view of commuting collective farm-market traders and bigger entrepreneurs in the vast shadow economy of Soviet Central Asia. Consequently, when in 1991 those borders became international borders and were gradually turned into barriers to transit, trade, work migration, and cross-border kin relations, the region suffered from this break-up of a formerly integrated economic space.

\footnotetext{
${ }^{24}$ The case study in Shugnan, GBAO, Tajikistan, produced credible allegations of "reparcelling" the drug turf with the involvement of border guards under Russian command, possibly special temporary units of contract soldiers.

25 The Feghana valley was not an integrated economic zone in the Soviet Union; the official state economy in terms of both production and trade was organised vertically and horizontal links between the republics were insignificant. However, in terms of small-scale bazaar trade and the informal or shadow economy, links were important and administrative borders did not pose any barrier to this kind of economic activity.
} 
Owing to the many enclaves in Batken oblast even internal communications are seriously hampered since all main roads pass through the territory of other states (Tajik and Uzbek mainland and exclaves). Competition for natural resources between the administrations of agricultural units translated into conflicts between nation states over sovereign territories. Disputed or simply absent demarcation of borders is a serious problem between the neighbouring countries. Creeping migration from densely populated enclaves into neighbouring "vacant" territories already an issue in the Soviet period - frequently causes social and political tension.

In Batken oblast the border regimes of three countries are directly impacting upon a whole range of local conflicts. Among the main concerns are internally interrupted communications with the rest of the country because of the enclaves, and the multitude of border related checkpoints on the transit roads (including border guards, police, customs, and veterinarian inspection of three countries). Checkpoints are a frequent trigger for demonstrations, at times bordering on riots, between local (Kyrgyz, Uzbek and Tajik) communities and the respective (Kyrgyz, Uzbek and Tajik) state authorities setting up or relocating checkpoints. Disapproval is complex and different groups have different grievances. Hefty bribes and the arbitrary conduct of officials is a concern mainly for commuting poor farmers and small traders. Bribes are taken in addition to official fees imposed by central governments for transiting their territory. Particularly Uzbekistan has used official transit fees to exert political pressure on its Kyrgyz neighbour to win concessions on other issues (e.g. irrigation water or the closure of border markets). ${ }^{26}$ To the better off and well-connected traders, smugglers and criminal entrepreneurs, the corruption of officials is not the problem (but instead are a solution to the problem). Changing location and the staff of posts, on the other hand, may make their business less reliable. Two newly established posts on the Tajik-Kyrgyz border closed to Aksay were allegedly "taken out" in January 2003 on the initiative of such local big men.

Competition over natural resources, mostly irrigation water and arable land, are politicised and sometimes aggravated in border zones. Demographic pressure on those natural resources is highest in areas where a combination of high birth rates and political or geographical borders limit access to land. This is first and foremost the case in the Tajik enclave of Vorukh and the Uzbek enclave (populated almost exclusively by ethnic Tajiks) of Sokh in Kyrgyzstan. Some Kyrgyz areas in the vicinity of the enclaves, however, suffer a similar problem of access to arable land. On one occasion in 2000 , armed forces intervened on Tajik and Kyrgyz sides in the vicinity of the Vorukh enclave in order to protect the interest of "their" farmers who quarrelled over a territory long disputed between the communities. Most importantly there are hardly any local institutional arrangements charged with negotiating and decision making in these disputes. An exception is the joint Parity Commission set up in 1997 to regulate demarcation issues between Tajikistan and Kyrgyzstan. ${ }^{27}$ The

\footnotetext{
${ }^{26}$ For a most recent case, see BB 2004; BBC Monitoring 2004

${ }^{27}$ A similar commission had been established first between Uzbekistan and Kyrgyzstan back in 1994 but has been defunct since the incursions of 1999.
} 
effectiveness of the commission depended, however, on political backing from the respective capitals, a backing that has not been granted continuously.

A core concern with regard to border related issues is one of how national or systemic security is perceived among the governing elites in the respective capitals. For Uzbekistan, borders are a core institution to protect the stability of a vulnerable pseudo-Soviet system that depends on tight political control and a subsidised rump economy. Mining and militarising the border with Tajikistan and Kyrgyzstan are meant to protect the system against political and ideological incursions. The border regime is also meant to protect the subsidised national economy from the market pressure of neighbouring "capitalist" economies (drainage of cheap products like fuel). This is why the Uzbek government since 2003 has been targeting and closing border bazaars with Kazakhstan and Kyrgyzstan in particular. Tajikistan, on the other hand, is as a nation state still extremely vulnerable to the instability in Afghanistan and political, economic or even military pressure from its stronger neighbours. ${ }^{28}$ Thus far it has outsourced national security to a certain extent to Russian (border) control.

These perceptions of security in the centre inform policies that have an impact on the way local communities in the target regions deal with conflict. They are, however, beyond the reach of local measures.

Thirdly, there are the interstate borders between the south of Batken oblast in Kyrgyzstan and the northern part of the Tajik Rasht valley, and the interstate border that separate Southern Kyrgyzstan from the northern part of Tajik GABO. In the first case, high mountains mark the border, and communications are limited to passes negotiable on foot only during the good weather season. This border rose to some prominence during the IMU incursions into Kyrgyzstan and Uzbekistan in 1999 and 2000. Allegedly, this route is used for drug trafficking from Tajikistan to Kyrgyzstan. It is also used by the Kyrgyz population in Jirgatal (Tajikistan) for seasonal migration to Kyrgyzstan. In the second case, there is a highway connecting Osh in Kyrgyzstan to Murghab and Khorog in GBAO. This is the main route of supply for the Murghab region in Tajikistan, and shuttle trade between Osh and Murghab is one of the very few income opportunities in Murghab. Recently Kyrgyz traders from Murghab complained that the many checkpoints between Osh and Murghab impose unfair and heavy informal "taxes" which endangers trade and livelihoods.

\section{Conflict transformation - measures available}

From a peace and conflict perspective, the Afghan-Tajik border and the threecountry triangle of the Ferghana valley deserve the most attention.

On the Afghan-Tajik border there are two main risks to cross-border stability. (1) The failure of state building in Afghanistan and resumption of civil war; and (2)

\footnotetext{
${ }^{28}$ See Freizer, Abdullaev 2003; Grävingholt 22.03.2003
} 
uncontrolled effects from relaxing the border regime and encouraging contact between the border communities.

The first issue is of obvious regional political importance and can only be targeted to some extent by local development programmes. Making the new state work on the ground and contributing rather than contesting its legitimacy are core principles suggested in this report. For the border issue this approach has immediate implications, however. Thus far, the border on the Afghan Badakhshani side is very poorly controlled. Some border areas - like the Ghuaran district controlled by the notorious commander Kariwadood - are completely out of state control and are heavily involved in criminal cross-border activities. Those territories have to be brought under Afghan state control. Border control cannot be left to Tajik or Russian forces alone.

The second issue puts local development to the fore. Smart opening of borders that is opening the border to those forces that connect rather than to those that divide - is to some extent a technical infrastructure problem. A number of bridges over the border river are planned or under construction at time being. Training and equipping border guards particularly on the Afghan side will be an important aspect of future border security. On the Tajik side there are some indications that the Russian border guards might be replaced as the first line of border control by Tajik units. The training, equipping and financing of such units will be a huge problem that the Tajik state will be unable to accomplish by itself. ${ }^{29}$ The communities in the border regions on the Tajik side univocally express their fear that, while Russian border guards might be suboptimal in their performance, their Tajik colleagues would be absolutely not up to the task and no challenge to criminal cross-border activity.

Technical and organisational problems are not the only aspect to examine in order to avoid negative fallout from relaxing the border regime. In the region under scrutiny, social and economic aspects are equally important. Ignorance, prejudice and among the Gorno Badakhshan Pamiris a memory of historical oppression certainly counts as a divide in relations with the Afghan neighbours. Fear of wellorganised armed groups involved in drug trafficking is also an important feature of the way border communities relate to their neighbours today. Except for the established criminal cross-border networks, there appear to be no institutional arrangements to regulate arising conflicts. Donor interventions and NGO activity should target both the lack of trust and the institutional gap. Institutionalisation of well-organised and strictly controlled border markets could be a step into the right direction. Intensifying the transfer of technical skills and know-how from the Tajik side to communities in Afghan Badakhshan via NGO activity would also be well received.

\footnotetext{
${ }^{29}$ A visit to two formerly Russian border units taken over by the Tajik army in 2003 on the Chinese border paints a worrying picture: soldiers without proper winter clothing were digging for Tersken to heat their barracks. Only their superior, a Russian sergeant left behind by the Russian border guards, possessed a weapon. The soldiers claimed to get three live cartridges per person per two-year service. Cf. Eurasianet.org 2003
} 
This study was unable to establish how significant existing horizontal (mostly kin-) networks connecting the neighbouring communities in Afghanistan and Tajikistan still are.

The problem with border regimes in the Batken target area is of a very different nature than the one just described. The main concern for conflict transformation is (a) the irrational patchwork arrangement of bubbles of sovereignty for three states; (b) political manipulation and corrupt misuse of the border regime; and (c) the lack of effective cross-border institutional arrangements to solve local conflicts locally.

A comprehensive solution to this complex problem is not on the agenda of the states today. The task of today is to mitigate against the negative effects of complex borders for the local population and to avoid a worsening of existing conflicts because of the border regime. Any requirements concerning border regimes, at least to a certain degree, concern the central state. Lobbying for the professionalisation of border control, avoiding the misuse of check points and limiting their number should all be done only closely co-ordinated with organisations of regional diplomatic standing, i.e. UNDP and OSCE.

The functionality of existing cross-border institutions - like the Parity Committee charged with demarcation related issues - is important to ease tensions and resolve conflicts. Their work and particularly their power to decide and implement decisions should be backed in any way possible. Thus far, there are hardly any official institutions capable of negotiating in cases of cross-border conflicts. Contact is usually established via informal local institutions - like networks of traditional wrestlers, or community leaders. The leaders of the administration of the neighbouring communities do not have any routine in meeting each other to decide local problems ${ }^{30}$ Creating such a forum might be possible but it makes sense only if it is reliably connected to executive bodies capable of sanctioning and implementing recommendations derived at those forums. To foster the institutionalisation of crossborder cooperation the GTZ Programme should connect to existing programmes of international organisations working in all three countries. UNDP, for example, has recently developed a cross-border conflict prevention approach that is thus far, however, limited to border regions between Kyrgyzstan and Tajikistan. ${ }^{31}$ The fact that UNDP as part of this approach has created the institution of "Peace and Development Advisor" should be used for inter-agency coordination on cross-border strategies.

A parallel strengthening of contact between civil society actors, community leaders and other respected figures has been initiated by the SDC financed project of Ambassadors of Good Will. ${ }^{32}$ The OSCE in Sogd region of Tajikistan has also been working with contact approaches between community leaders.

\footnotetext{
${ }^{30}$ For a recent example of successful ad-hoc mediation in the vicinity of Chorkuh/Ak-Sai see Vecherniy Bishkek 2004.

${ }^{31}$ See Government of the Kyrgyz Republic, UNDP 2003

${ }^{32}$ This initiative is part of the RDD framework project of SDC (Regional Dialogue and

Development Project in the Ferghana Valley).
} 
In terms of border related problems, civil society can, however, only be a back up to changes that require the political will of governments in order to ease tension and find sustainable solutions to conflicts. The latter is beyond the scope of food security and conflict management development approaches. Connecting to lead agencies with diplomatic influence is therefore an important precondition to any direct involvement.

\subsection{Criminal economy related conflict arenas}

Three types of economic activity should be differentiated in their relation to conflict and peace capacities of local communities in the target region. Firstly, there is the official economy, state sanctioned, law abiding, and tax paying. In the target regions in all three countries this economy is marginal (Kyrgyzstan, Tajikistan) to nonexistent (Afghanistan).

Second, there is the informal (also "shadow" or "black") economy which is not state sanctioned, not protected by the law and is non-tax-paying. It avoids the state rather than challenging the state's monopoly of violence. Activities of the informal economy range from local coping strategies to the "second economy" of official enterprises or the venality of posts and services within the state administration. The informal economy in the target regions is dominant in structuring the economic incentives and strategies of actors in conflict.

Last, there is the criminal (were there is a state) or (civil-) war economy that is distinct from official and informal activities by facilitating non-state violence as central asset of economic activity. ${ }^{33}$ This violent economy challenges core state functions, is non-productive, preys on the official economy and taxes the informal, unprotected economy and sells both violence and protection against violence as a service. Outright markets of violence are absent in Kyrgyzstan, have lost significance in Tajikistan, and appear, at least for the time being, to be on the decline in Afghan-Badakhshan.

The situation in Afghan-Badakhshan and Tajikistan remains fragile, and the borders between the informal and the criminal/war economy are blurred. In Tajikistan the dominant networks of patronage apply to both informal and violent economic strategies and it could be argued that the criminal economy has been successfully nationalised. In Afghan Badakhshan there is no state yet to fill the "enforcement gap" that the retreat of the former entrepreneurs of violence - the commandons turned businessman, teacher or security officer in uniform - have left.

\footnotetext{
${ }^{33}$ Some authors refer to this phenomenon as a market of violence. Elwert 2003.
} 


\subsubsection{Arena: Drugs}

The conflict analysis in the target regions established drug related issues as the main conflict arena within the informal and criminal economic sector for Tajikistan and Afghanistan. The arena includes production, refining, trafficking and consumption of opium poppy and heroin. It is closely connected to the arenas of "border" and "patterns of local governance" and the aspect of state building in particular. Here we will limit our focus to potential conflicts caused by the dynamics of production and trafficking on the Afghan Badakhshan side of the border. Problems related to drug trafficking in the Tajik target regions have already been discussed in the chapter on "borders".

\subsubsection{The problem}

The poppy economy in Afghan Badakhshan and drug trafficking through Tajikistan are highly complex issues of general relevancy for development prospects. Two excellent studies, commissioned by the GTZ, provide graphic accounts of the complexity of this economy from a household perspective in the AKDN/GTZ target areas of Afghan Badakhshan. ${ }^{34}$ We partially include their findings in the next section which discusses how the drug economy relates to the conflict processing capacities of local communities.

In Afghan Badakhshan the arena for poppy economy related conflicts has been dramatically affected by recent events, especially by the drought of 1998-2001 and by the Taliban ban on poppy cultivation in June 2000 .

The drought facilitated a concentration of land and other important assets in the hands of powerful local elites, thus speeding up a tendency which was already under way in war isolated Badakhshan due to a credit system that was very disadvantageous to resource poor, credit dependent households.

The Taliban ban on opium poppy cultivation caused a steep rise in opium prices. As a result, opium-refining specialists flocked into Badakhshan, the last area which was not under Taliban control, and poppy cultivation in Badakhshan increased and heroin production emerged.

Therefore, the rural elite and the poorer stratum of indebted households embraced the poppy economy - the former as a strategy to further accumulate wealth, the latter as a strategy to compensate for the losses they suffered from the drought. It was the combination of exhausted assets and accumulated debts with the sharp rise in opium prices that entrenched opium poppy production as a major livelihood strategy. This new strategy does not only refer to the cultivation of the plant but also to wage-labour opportunities arising from labour intensive poppy cultivation, and for few, to trade opportunities.

\footnotetext{
${ }^{34}$ Pain January 2004; Mansfield January 2004
} 
The end of the Civil War and the fall of the Taliban regime did not reverse the trend of new economic stratification and dependency of particularly the resource poor on opportunities connected to the opium poppy economy. Despite falling prices and closed borders for free-lance opium trade with Tajikistan, the opium poppy appears to have established itself as an integral part of local livelihood strategies traditionally relying on diversifying income.

Recently, we observed a growing professionalisation and concentration of the poppy economy which may be caused by "peace-time pressures", that is, by attempts of the emerging state or of international organisations to criminalise the poppy economy. Indicators for this process are the appearance of an estimate of $\mathbf{2 1}$ heroin courtyard factories, employing "foreign" experts, and allegedly being protected by regional (Kunduz) or central (Kabul) political patronage, and the professionalisation of the trade with Russian and Tajik business partners across the border.

Within this highly professionalised, interregional business, some local commanders appear to be sidelined as providers of security. ${ }^{35}$ On the other hand commanders like the already mentioned Kariwadood in Ghuaran, who managed to keep strategic border zones under their exclusive control, appear to be a crucial asset in the bigger cross-border narco-business.

Currently, the poppy economy can certainly be seen as an alternative copingstrategy for those affected by the drought. It thus eases pressure on other alternative strategies such as grain-deficit agriculture, the sale of livestock, local salary work, seasonal work migration, remittances from permanent work migration, seasonal credits (including unfavourable credits on future harvest) and mortgaging of land. Economically, a wide array of people has benefited significantly from the rise of the opium poppy economy, though to very different extents. For the resource poor, dependency may shift from traditional creditors (local shopkeepers, travelling traders) to new local big men who have accumulated land and traders professionalising in the opium poppy trade. This brings into being new kinds of patron-client relations.

Any successful but untargeted interdiction programme would most certainly have a very negative effect on the debt-dependency and food security of this resource poor group that only recently managed to upgrade their survival strategy to coping thanks to their access to the fringes of the opium poppy economy.

How do the dramatic changes in the local coping and accumulation strategies affect the political economy of conflict?

\footnotetext{
${ }^{35}$ According to an account that we were unable to crosscheck, a heroin factory in Jerm employs 40 security personal that work in shifts under central, not local command. When there was an attempt to close the factory in 2003, on the initiative of a commander from Kunduz, it was the intervention of a well-positioned political patron in Kabul that made sure the factory reopened and the security personnel was rearmed.
} 
A commonly held (and in a global comparative context, also well-founded) expectation is that entrepreneurs of violence often utilise low-weight high-value commodities like drugs to sustain violent conflict for their economic ends. ${ }^{36}$ The fieldwork on conflict at community level does somewhat surprisingly not support this rather simplistic picture. While the economy of Badakhshan is far from post-war (the threat and application of violence still figures prominently in economic interaction), it appears that thus far the rise of the opium poppy economy has relaxed rather than aggravated tensions within and among communities. Even among actors more heavily involved in the professional side of the business we do not as yet have evidence of turf-wars, fights over the control of heroin factories or violent competition over taxation of the opium poppy economy. ${ }^{37}$ Even the sporadic law enforcement attempts by the state (attempted closure of heroin factories) or by allied forces (eradication attempt by British forces in 2002) did not lead to any violent conflict. This relative quiet is likely to change though, when state-building and interdiction measures will increase pressure on the market and encourage further concentration and professionalisation. A growing dependency of the resource poor farmers on the patronage of drug-related big men would change existing rules of the game. Economic debt dependency on creditors would change to political dependency on patronage to secure economic survival. ${ }^{38}$

The most important immediate risk for violent conflict connected to the opium poppy economy are developments around "lost territories" controlled by renegade commanders with significant stakes in the professional part of the cross-border market.

Some small-scale tensions within communities concern consumption issues. In Wakhan, were consumption is widespread and a huge economic problem for families with addicts, religious pressure against consumption has been rising, and tension between the generations, where the young have voiced strong dissatisfaction with the addiction level of the older generation, are growing.

\footnotetext{
${ }^{36}$ Berg September 2003

${ }^{37}$ Unverified news just in quote deputy Minister of the Interior Hilalludin Hilal connecting a recent violent clash in the Argo district of Badakhshan with allegedly 20 casualties on the beginning of a turf war (here between district police chief and district head of administration) Tarzi 2004. The same news compilation quotes the director general of Afghanistan's Counternarcotics Department, Mirwais Yasini, on the destruction of a heroine laboratory and seizure of two tons of drugs as a joint operation of British trained Afghan special police and US military in Shurabak, Badakhshan.

${ }^{38}$ Reports from other parts of Afghanistan, the southern province of Helmand for instance, do support the interdependence of drug economy and high levels of violent conflict (see Rashid October 2003). This observation only adds urgency not to miss chances to prevent the Badakhshan opium poppy economy from fuelling sustainable violence.
} 


\subsubsection{Conflict transformation - measures available}

The first conclusion to draw from the analysis of diversified livelihood strategies, to which the complex opium poppy economy has been integrated on various levels, is: there is no magic bullet fix to this problem. This sobering conclusion is particularly highlighted by Adam Pains' word of caution on the principle constraints on development opportunities of mountain economies. Poppy has become, like elsewhere potatoes or technical innovations, a potentially prolonging asset in diverse livelihood strategies of mountain societies. However, with growing population pressure and contact to the outside world, the coping strategies of mountain economies will, no matter what, depend increasingly on seasonal migration and cash remittances from permanent work migrants. One might wish to add the somewhat theoretical option for Badakhshan of a state policy of budgetary transfers and redistribution of resources to under-structured regions (as was the Soviet case with Tajikistan).

Any measures targeting sustainable alternative livelihoods to poppy cultivation, refining, and trafficking have to keep this in mind. An integrated and unorthodox strategy is required. Conflict transformation and conflict avoidance are two crucial aspects of such a strategy: the risk that drug economy and violent conflict could form a vicious circle where one reinforces the other is still present.

An integrated approach requires the combination of immediate and middle term measures with long-term development engagement.

Short and middle term measures:

(1) Law enforcement in stateless, "lost territories", conducted by well trained and equipped national forces, backed up by symbolic international support.

(2) Interdiction of heroin factories, (state-) drug traders and their patrons at regional or national level. Given the convincing allegations of high-ranking political patronage for some parts of the big business these measures would have to be closely monitored by international agencies of the highest diplomatic standing (UNODC) to avoid "turf wars by state means".

(3) Back-up emergency measures against sudden food-insecurity and debt accumulation in the aftermath of decisive interdiction for the most vulnerable parts of the poppy economy.

(4) Moral campaign against drug production, trafficking and consumption via religious authorities and state agencies.

Long-term initiatives in addition to ongoing "classic" food-security targets (agriculture, infrastructure, access to markets, SME growth, backing local selfgovernment) are directly linked to conflict transformation:

(5) Backing existing coping strategies, particularly seasonal work-migration. This important and developed coping mechanism within diverse livelihood strategies needs further investigation. Back-up strategies which deserve 
further study and potentially reinforcement could be: establishing a fair and reliable system for credit, providing access to information on market requirements, providing vocational training for required skills, and enhancing communication and infrastructural conditions.

(6) Backing safer options for "voice", particularly fostering lobbying and collective action capacities on the side of dependent farmers/sharecroppers vis-à-vis traders and creditors. Helping the more dependent part of the population to better organise the representation of their interests would be particularly important in order to enhance alternative livelihood strategies after successful interdiction in Badakhshan. It should be stressed, however, that rising the organisational capacities of dependent and powerless groups bears the risk of socially disembedded conflict and usually is conditional on a state framework providing a monopoly of violence and the rule of law. Otherwise empowering the disempowered can go very wrong for the latter.

(7) Backing civil alternative livelihood strategies for former entrepreneurs of violence. Former commanders that have demobilised and are now establishing themselves as businessmen and investors set a good example to others that got used to making a living (at least in part) by the gun. ${ }^{39}$ From the point of view of conflict transformation, development strategies have to take into consideration both the winners and losers of changing conditions.

\subsection{Natural resource related conflict arenas}

The most visible conflict arena in the target regions is competition over natural resources. Local communities depend to a large extent on subsistence agriculture and livestock keeping. With the break-up of the Soviet system that had guaranteed centrally planned, centrally subsidised and centrally equipped intensive farming, pressure on the two key assets of highland agriculture - irrigation water and arable land - increased. Today, the decay of Soviet infrastructure, most importantly of the machinery of the state farms, of the irrigation systems and of the land communications, further aggravates the problem.

Pressure on scarce land and irrigation water is further aggravated by two additional factors: following privatisation ${ }^{40}$ a massive shift from state-sponsored cattle breeding and pasturing to survival and subsistence agriculture occurred, particularly in Batken oblast. Secondly, well-established alternative or additional sources of income such as salary jobs, social mobility and social welfare, have dropped significantly in Batken and in Tajikistan following the disintegration of the Soviet Union.

\footnotetext{
${ }^{39}$ see Ashur Bek case in Wardooj-e Bala case study, Afghan Badakhshan report (p. 22ff)

${ }^{40}$ Under the land privatisation process in Tajikistan, sovkhoz land has not been automatically distributed as it was in neighbouring Kyrgyzstan. Instead, people have to apply for land individually. Ownership de facto stays often with collectives rather than with individuals. In Kyrgyzstan agricultural land was privatised automatically among households.
} 
The situation differs in Afghan Badakhshan as Soviet style collectivisation did not take place. Agriculture has been, however, the most stable and common income source in otherwise shifting strategies. Income alternatives to agriculture and livestock keeping have been reduced in reliability and availability by 20 years of war and by the recent three-year long drought.

Today, for all three countries, the most important strategy to cope with lack of additional income is seasonal and permanent work migration and reliance on remittances from family members who have migrated.

It should be stressed that the growing dependence on limited, scarce or insufficient resources is, from a conflict management perspective on food security, only part of the problem. The aspect of how access to available resources is regulated, and how utilisation of those resources is organised are as important. While scarcity of and competition over resources may be a serious problem for communities and a cause of social tension, it is mismanagement of scarcity and competition that leads to conflict escalations.

\subsubsection{Arena: Water}

\section{The problem}

Since the arenas of "irrigation water" and "arable land" are closely interlinked we will focus first on water related issues in Batken oblast in Kyrgyzstan and GBAO in Tajikistan, where the issue has been identified as a central problem by the local research teams. We will turn to the case of Afghan Badakhshan and the Rasht valley in Tajikistan to exemplify conflicts arising around access to and distribution of land. Because of the interdependency of both arenas we will develop conclusions for conflict transformation jointly for both arenas.

\section{Batken}

Water is the most important natural resource in Batken oblast. The agriculture of the oblast depends heavily on irrigation ( $50 \%$ of cultivated land is irrigated). ${ }^{41}$ From the local perspective there are four factors adding to conflicts about irrigation water. Most relate to access and utilisation, and not to availability. In other words, the focal point for understanding conflict about water is organisational rather than technical. We identified the following four organisational problems:

\footnotetext{
${ }^{41}$ Kazakhstan's and Uzbekistan's economies also depend directly on the water originating in the Alai Mountains which mark the border between Kyrgyzstan and Tajikistan. In the Soviet Union water quotas regulated distribution between the Soviet republics; today these quotas are matters of hot dispute between the national governments. However, interstate disputes on the national level are explicitly not the subject of this report. For a well informed overview over the subject see ICG 30.05.2002.
} 
a) The neglect of maintenance and control of the irrigation system by the responsible state agencies (Irrigation Departments on district and oblast levels, the Ministry of Agriculture and Water at a central level). This neglect has three main reasons. First, lack of funds (aggravated by the reluctance of consumers to pay their fees and by corruption within the system); second, unclear division of responsibilities between the communal and administrative levels; and third a lack of organisational and technical competence, particularly at the district level.

b) Local coping strategies gone wrong. Community-based mobilisation for selfhelp led to uncoordinated, inefficient and wasteful exploitation of irrigation water - mainly by digging wild canals bypassing the official system and making holes into the remaining concrete canals. Co-ordination of collective action (constructive or destructive), monitoring of binding decisions and sanction capacities are confined - at best - to the range of social control within a community. Such informal and traditional institutions capable of mobilising or containing collective action vary, depending on region and ethnic groups. Some institutions are shared by all groups in Batken, for example the council of elders and the honoured institution of traditional wrestling (Kurosh). Others are specific to ethnic groups. Among Tajiks there is the well-structured neighbourhood organisation mahalla, among Kyrgyz the traditional "brigades" headed by onbashi (brigades of 10 ) and juzbashi (brigades of 100). A new and rather formidable organisational force are the patron-client networks turned into NGOs, as in the case of Jany Jer. A former factory boss turned patron organised former factory workers into an NGO and mobilised collective financial and physical effort in order to build a powerful new canal to irrigate acquired land. ${ }^{42}$ The state has refrained thus far from decisive interventions even in cases were new "wild" canals that threaten to cause outright conflict with downstream users were built on private or community initiatives.

c) Damage to the existing irrigation systems by demolition of canals and the sale of the non-ferrous metal fittings and pumps as scrap, most often committed by young men. Such incidents happen within communities that have weak social control and only weak capacities for internal self-policing. Such acts lead to the desolation of irrigated land in the vicinity of the settlements of those communities. Typically, communities with weak social control are young communities that were brought into being by Soviet policies of resettling young families from different regions as a workforce for new collective farms. However, the lack of a feeling of ownership over the formerly state run irrigation system - a lack of responsibility for something that was taken for granted in Soviet times - is a general problem within communities. This significantly relaxes the willingness to contribute to the maintenance of the system beyond the directly exploited segment. In

\footnotetext{
${ }^{42}$ See case study Alga-Halmion-Jany Jer zone, Batken report (p. 28ff)
} 
general, the reluctance to agree on and trust in unspecific reciprocity ${ }^{43}$ is a serious hurdle to efforts like organising functional Water User Associations and collecting fees for services transgressing the village community.

d) Complex borders and enclaves have a serious impact on local conflicts about access to and distribution of water. The fact that there was a regional integrated irrigation system in the past now invites its misuse for political games of the countries involved (for example, by interrupting water supplies in disputes about land or by trading the relaxation of transit for more water). The fact that the neighbouring nation states manipulate competition over vital resources for political ends carries the risk of encouraging ethnic interpretations of resource conflicts. Thus far (perceived or actual) prejudice and discrimination do not figure prominently in these conflicts. Enclaves also pose a logistical problem: constructing new canals or pipes is often only possible with the consent or co-operation of other countries' administrations. In principle this interdependency also opens windows of opportunity for winwin solutions. A lack of institutional mechanisms to go ahead with meaningful co-operation is the main problem in this regard. The research did, however, also discover some positive local examples of institutionalised cross-border co-operation between communities that led to reliable and durable (mostly unwritten) contractual relations on the distribution of available irrigation water. ${ }^{44}$

In summary, the main issue that puts water prominently on the list of potential or actual conflict arenas in Batken oblast is closeiy linked to the problem of modes of local governance (analysed on page 21ff). Neither the state(s), nor civil society (beyond partly functioning village institutions) are capable of processing conflict about access to and distribution of irrigation water according to the functions of constructive conflict processing spelled out above: negotiation $\rightarrow$ procedure $\rightarrow$ decision/agreement $\rightarrow$ contract $\rightarrow$ monitoring $\rightarrow$ sanction.

\section{GBAO}

Problems regarding access to water, both for irrigation and drinking, are a main issue of discontent and tension within and between communities in many places covered in the research in Tajikistan. However, it need not always be a serious risk for escalation: We focus on the case of GBAO to exemplify that the local perception of critical conflict does not necessarily mean that this conflict arena is at risk of escalation.

\footnotetext{
${ }^{43}$ Exchange relations in which a service or good is delivered without expecting compensation in direct exchange because trust in returned value is de-personalised and generalised. Paying general taxes and trusting in unspecific state services is an example of unspecific generalised reciprocity.

${ }^{44}$ The case of traditional agreement on distributive schedules as explained in the Kyshtut case study, Batken report (p. 69ff)
} 
Competition over scarce irrigation water was reported to be most dramatic in the district of Porshnev. The representation of the seasonal conflict over distribution by local respondents was quite dramatic, claiming "to wish to die" each time during the irrigation season, or citing a popular poem according to which brothers turn into sworn enemies during irrigation seasons.

The research confirmed that irrigation water was, indeed, insufficient to irrigate the fields of all communities and that the (technical) distribution system was far from optimal. At the same time the research also revealed that this serious seasonal conflict is reliably processed by a functional arrangement of local governance. Annual negotiations of accepted representatives of the interested parties (heads of communities and officials of the local government) are institutionalised and the dispute is carried out via a widely accepted, though informal, procedure for setting the rules of how to arrive at a binding decision in the dispute. This decision is called a "grafik" or water distribution schedule. It is formalised in writing and receives contractual status by the formal approval of the representative of the local government (the document is stamped). Monitoring of the contract is carried out by the communities themselves and sanctions, if need be, are applied by more or less functional social control. Conflict is fierce every year and conflict is reliably processed every year. Different to negotiation, procedure, agreement and control based exclusively on informal institutions confined in their impact to just the village, in the given case the formal involvement of an official district body appears to facilitate binding inter-communal agreements.

The case of GBAO is particular, however, in the sense that geographical availability of arable land is so limited that land - the real drive behind competition over Irrigation water - never had the same function as a core resource of the local economy as it has in other regions.

\subsubsection{Arena: Land}

\section{The problem}

All three countries in which the research took place are agrarian countries. Distribution of, access to and utilisation of land, pastures and woodlands is of key importance for the livelihood strategies of the vast majority of the population. Not surprisingly, conflicts about land figure prominently in most locations.

In contrast to conflicts about water, conflicts about land must be seen within a context of de jure and de facto property rights. In this regard the post Soviet regions are significantly different from Afghan Badakhshan where the private ownership of land has never been abolished. 
The privatisation process has by and large been accomplished in Kyrgyzstan. Conflicts about land in Batken oblast are related less to land tenure or legal titles than to issues related to its utilisation, and to disputed land in the vicinity of borders. Attempts to create facts before demarcation is accomplished are a frequent cause for conflict. Such attempts are both state sponsored (encouraging the resettlement of farmers in disputed territories by providing them with newly built houses) and community driven (e.g. creeping migration and settlement in disputed areas).

In Tajikistan the privatisation process is still in many regards pending. Land remains the property of the state and it is only upon application, distributed for life-long use. According to a recent law, all state farms are to be privatised by the year 2005 . However, this goal will not be reached. Furthermore, empirical evidence shows that the privatisation of state farms does not necessarily lead to a change of regime for the exploitation of land and labour. Often the old/new directors of collective farms exercise de facto property rights. For individual farmers the rights to use and transfer of land are poorly regulated and poorly protected. Land tenure insecurity remains high in Tajikistan.

In Afghanistan land ownership is regulated by three unreliable, partly competing and partly integrated legal principles: local customary law (adat), universal religious law (shariat) and universal state law. Over the past two decades state law proved to be even more unstable and unreliable than adat or the ever changing interpretations of the shariat. After the adoption of the new constitution in November 2003 references to religious law have been officially abandoned after heated debate. Irrespective of the fact that there is a long tradition of property rights and of legal titles, security of land tenure remains weak. Disputes caused by competing interpretations of different codes of reference and by attempts at manipulation are common, and the use of force for enforcing one's interpretation of what is right often occurs.

We will now focus on the two areas where land tenure related conflicts are central to peaceful development and stability - Rasht in Tajikistan and Afghan Badakhshan.
"The crucial point about the land law, which has lead to huge inequalities of distribution, is that, in Tajikistan state farms are not broken up and land automatically distributed as in neighbouring Kyrgyzstan. Rather people have to apply for land individually. Thus the state farm is not broken up into a number of equal plots corresponding to the number of households, but rather simply parcelled out to whoever has the money, foresight, and influence to apply first. "

Robinson, MSDSP 2002

"[Land tenure insecurity may be] a case of clan heads carving up local pasture for new cultivation, land that poorer villagers thought was theirs to share, that the government thought was its own to distribute, that visiting nomads thought was theirs to graze and often have documents to "prove" it - documents that may conflict with others issued at different times, with the law, or with human rights and justice norms. At this point in time, multiple claims, each with its own historical legitimacy, may exist over the same land. The law, and the documents or testimony it generates, is plural, complex, uncertain, incomplete and currently unenforceable." Wily March 2003: 1

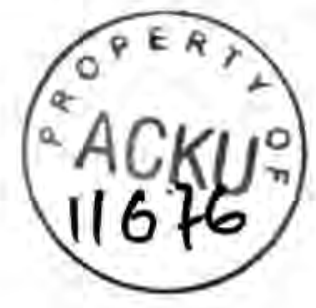




\section{Rasht $^{45}$}

Distribution of access to land in the Rasht valley is marked by inequality and social stratification that is, even in the Tajik context, startling with more than $50 \%$ of families left without land for rent or permanent tenure. High informal fees to get state certification of property rights and confusion over the legal security such a certificate actually grants discouraged many families from applying for privatisation (see quotation from Robinson 2002, text box on page 46)

The rural elite in Rasht have been shaped by the Civil War: Local big men such as influential religious figures and/or former combatants, many of whom have protection from those members of the former opposition who were co-opted into high positions in Dushanbe, heavily influenced the process of land distribution in their favour. In addition, it is mainly access to land that provides the opportunity to earn additional income. Only families with access to land can afford the initial investment needed to engage in trade on cash-markets in Dushanbe or to send family members on work-migration to Russia. As a result, social stratification is growing and a large number of the population is deprived of participation in any kind of meaningful development process. An additional factor contributing to a precarious social situation in Rasht is the fact that internal work migration is not an option for the population of the former opposition regions. For them, access to jobs in Dushanbe and Khatlon oblast is usually blocked because they belong to the former "opposition regions".

At present, local elites are not violently contested by the dispossessed. If disputes arise, they are usually resolved in favour of the powerful, both informally and formally through the actions of local government. ${ }^{46}$ From a development perspective one may argue that the absence of constructive conflict causes a situation that is steadily deteriorating. Conflict is not processed; it is power-locked.

\section{Afghan Badakhshan}

Land tenure in Afghan Badakhshan is characterised by complex legal pluralism. The problem with land tenure conflicts is not an absence of a legal system. It is, firstly, the parallel existence of at least three types of codified rights (written and unwritten customary law, religious law and state law). Secondly, no matter whether conflicts are dealt with by councils (Shuras), commanders, administrators or traditional judges, they all have to take into account the real power of the conflicting parties. In that sense, none of the available procedures for conflict resolution is reliably shielded from power politics.

\footnotetext{
${ }^{45}$ See Tajikistan study, conflict arena land, p. 33ff.

${ }^{46}$ See case study Tavildara, p. 35
} 
The case of a dispute about a forest in Wardooj-e Bala is a telling example of a legal pluralism open to power plays. ${ }^{47}$ First, a stronger community disputed the rights of a weaker community to exclusively use a forest for wood collection and pasture. The weaker community did not succeed in enforcing its rights by self-help and brought the case first to the (demobilised) local commander, who refused to get involved, and then to the new district administrator, the wolliswol. The latter resolved the conflict by a compromise that in fact cemented the status quo achieved by violence rather than the status quo ante violence. Though the weaker community denied the fairness of the decision it accepted the ruling but did not re-establish neighbourly relations with the stronger community. Finally, mediation between the two community's leaders, facilitated by a third community Shura, settled the matter and relations were re-established.

Thus far, the recently re-established representatives of state authority do not (yet?) offer neutral, transparent, procedural and durable conflict resolution mechanism. Years of "commandon-administration" have deeply discredited official institutions such as courts. Most people therefore turn to customary law and traditional conflict management institutions, including violent self-help.

Bringing in the real power of commanders may be a tempting alternative for the party standing less chances of winning by customary procedures. The problem with customary conflict management is that it "[...] is rife with practices that favour wealthier elites, men and dominant ethnic groups" ${ }^{48}$ While customary law appears to have a sound normative foundation with regard to farmland it appears to be much weaker and more disputed with regard to the more complex issue of differentiated, sometimes seasonal rights of access and utilisation of pastures and forests.

The exploitation of ethnic or religious difference to justify deprivation of rights or even violent action against opponents in land tenure disputes is a further high risk of such power-locked and contradictory normative and legal codes. The research in Afghan Badakhshan produced evidence that this practice has a legacy of at least the past 20 years and, though less violent of late, appears to still be a strategy applied in some districts with multiethnic or multi-faith communities. ${ }^{49}$

\section{Conflict transformation - measures available}

\section{Availability and organisational development}

Reliable and peaceful processing of conflicts about land and water is a precondition for stability and development. Two sets of measures facilitating conflict transformation can be identified: (1) physical and technical measures enhancing availability, access and utilisation of the resource, and (2) organisational

\footnotetext{
${ }^{47}$ See Afghan Badakhshan report, case study Wardooj-e Bala (p. 22 ff)

${ }^{48}$ Wily March 2003: 3

${ }^{49}$ See case study Khustak, p. $31 \mathrm{ff}$
} 
development making technical improvements possible in the first place and sustainable in the long run.

The analysis of the conflict arena "water" in particular revealed that the success of physical and technical measures with regard to conflict transformation and to sustainable food security essentially depends on successful investment in organisational development. The organisational development of distributive institutions first and foremost refers to enhancing the five functions of good governance essential for reliable conflict transformation: negotiation, procedure, contract/formalisation, monitoring and sanction. Conditioning substantial funding of Water User Organisations on the successful accomplishment of seven milestones of organisational development (institutionalisation) by the World Bank sets a good example of a strategy that uses material incentives to push for the institutionalisation of rules that are also conductive for better conflict management in resource distribution. However, targeted investment in technical capacities, particularly in the field of monitoring contractual agreements, can be an equally important contribution to successful organisational development. Even the best agreements on irrigation water distribution, formalised in legally binding contracts, may lead to bad conflict unless there is a transparent, reliable and neutral monitoring of the implementation of the agreement (for example, quantity of extracted water, time of extraction). The setting up of such monitoring may require technical investment.

The strategy of prioritising organisational development and institutionalisation of rules and procedures over material and technical assistance is vulnerable to strategies employed by other donors working in the same field. The example of parallel and uncoordinated engagement of SDC (attempting to target conflict transformation between ethnic communities via the development of institutionalised negotiations around jointly building a new canal) and UNDP (targeting the same conflict around the distribution of water by installing a new pump for the group suffering from water shortage) shows how long-term investment in organisational development is condition to an integrated and co-ordinated donor strategy. The identification of lead agencies for certain fields that are vulnerable in this regard would be helpful. For the local success of the WB programme in Batken, for example, it is essential that other donors do not start investing significantly in Water User Associations (or, worse, in alternative organisations that copy the functions of the WUAs) before they have accomplished the seven steps of improving their institutional functionality.

Last but not least awareness raising, information and training are important aspects of making organisational changes work. Communities must understand why changes in the organisation of resources are necessary and how those changes are in their best interest. It is also crucial to raise awareness of the value of formerly state-administered resources. Local ownership is in part a question of formal legal entitlement but it is also a question of understanding and feeling responsibility. 


\section{Guarantee of property rights}

In the context of the conflict arena of "land", a cornerstone factor for food security and conflict resolution are guaranteed property rights that reliably protect ownership of land.

Property rights must be protected by legal principles (state and/or customary law) to be effective. Without local ownership of key resources and of the infrastructure required for their access and utilisation, the situation remains at best ineffective and at worst conflict prone.

For conflict transformation, legal security is crucial. Legal pluralism (like in Afghan Badakhshan) or fuzzy, unclear and systematically undermined land laws (as in Tajikistan) are problematic for long-term peaceful development.

Ambivalent rights that are arbitrarily protected or neglected by the state authority invite resource concentration in the hands of local big men. While resource concentration (or initial accumulation) by the more entrepreneurial minded may be a functional, albeit unjust aspect of economic development, unchecked accumulation by political entrepreneurs, patrons of the criminal economy or entrepreneurs of violence is not - unchallenged resource extraction by local big men is not an economic investment.

Towards unified legal systems that leave space for complex arrangements of utilisation

Property rights on land and on other crucial assets may be regulated by both, state laws and customary law. Often state law and customary law are blurred into a complex arrangement. Afghan Badakhshan, as exemplified above as a case in point. Here, however, customary law is clearly the senior partner in this arrangement, and state law is only just re-emerging. By contrast, in Tajikistan, which has been spared the Afghan experience of prolonged statelessness but experienced instead Soviet-style modernisation, the state law is the senior partner in the arrangement.

Both types, however, are far from being perfect. Both the Afghan and the Tajik arrangements clearly favour the rural elite.

In the context of state building, the streamlining and unifying of property rights for land are important aspects which should be backed by development programmes. ${ }^{50}$ Such endeavours, however, bear a high conflict escalation risk when encountering local legal practice that exclusively favours the wealthy and powerful and deprives vast parts of the rural population of exercising their official rights. Such practices maybe embedded in customary law like in Afghanistan or dis-embedded like in Tajikistan. The formidable adversaries of such legal reforms are not the weak and

\footnotetext{
${ }^{50}$ The GTZ, for example, played a leading role in establishing a system of cadastre (land register) in parts of the Caucasus. USAID financed land registration in Afghanistan in the late 1970s.
} 
dispossessed but rather the better-organised local elites with their dependants (clients). It has been argued, for example, that the initial rural upheaval in Afghanistan in 1978/79 was caused by the somewhat ambitious land reforms of the communist government.

What is better for conflict transformation: equally poor, or stratification and concentration of land?

The risk of elites violently defending their privileges against reforms is not only of concern for Afghan Badakhshan. As the analysis of the situation in Rasht valley makes clear there are three possible future scenarios with regard to the current situation of unfair, uneven and - for the landless $50 \%$ of the population unsustainable distribution of land. First, state enforced re-distribution of land; second, legalisation of the status quo; and third, leaving the situation in limbo. All of those options are suboptimal in that they bear clear risks of conflict escalation and/or of development blockade. The first scenario makes the rural elite, many of them with a past as violent entrepreneurs, unhappy. The second cements a development catastrophe for the majority of the population. And the third - the most likely scenario to be chosen by the government - will further increase stratification and dispossession.

For development operations targeting sustainable livelihoods, food security and conflict transformation, this situation is, obviously, a dilemma. A decision on prioritising either conflict avoidance over development opportunities or vice versa has to be taken. The question arises of how important equality is for conflict transformation. Thus far in Tajikistan (and for that matter also in Afghan Badakhshan) reconciliation excluded restitution. Instead it co-opted already powerful players from the opposition into an existing network of patronage that had taken over the central state. The chief criterion for the most important mechanism of reconciliation - i.e. co-optation - was simply power, not legitimacy. At the same time there is no proof that equity as guiding principle in land distribution is less prone to conflict. In Rasht, GBAO, Shurabad, most parts of Afghan Badakhshan and in the Tajik and Uzbek enclaves in Batken there clearly is not enough arable land to achieve food security for everyone even if land distribution was fair and equal. Particularly in Rasht, Shurabad and Afghan Badakhshan a concentration of land ownership is taking place. In those mountainous regions it is highly unlikely that sustainable alternative income opportunities - like industry or mass-tourism - will appear in the short, mid-and may be even long-term.

From the perspective of conflict avoidance and sustainable development opportunities a programme targeting the management and investment capabilities of big men turned latifundist's on the one hand and family planning, birth control and structured (seasonal and permanent) work migration on the other hand might be more effective than the fair redistribution of land. However, we feel that this question deserves further analysis. 
Detect institutional responsibilities and stick to them. And link state and society

A corner stone in any strategy targeting the enhancement of distribution, access, and utilisation of land and water is the identification of existing institutional responsibility. No matter how inefficient and flawed it may be - official and legal institutional capacities in donor-dependent regions can only be developed if the donors insist in their implementation on playing by the formal rules. To give a concrete example - certification of projects related to enhancing water distribution must be sought with the responsible department of local government even if there are attractive and more reliable shortcuts. This is particularly important with new, community based institutions that are of critical importance for connecting society with the state - like the World Bank sponsored Water User Associations. This may also include backing (training, funding, technical aid) for complex problem solving institutions like the one found in Porshnev, GBAO on water distribution.

However, the principle limits of community based approaches to conflict resolution are particularly evident with regard to resource conflicts. Without state involvement, it is difficult to charge traditional or customary mechanisms with a scope of impact reaching beyond the community level. Negotiations and compromises are possible but without procedure, formalisation and guarantee of contract there is a danger that they reflect existing power relations rather than accepted legal principles.

\subsection{Social conflict arenas}

Tension between social groups ${ }^{51}$ and between identity groups $\mathrm{s}^{52}$ is often perceived as both a cause and driving force of violent conflict. Ignorance, discrimination, intolerance or prejudice between groups is, indeed, an important aspect of conflict escalation. Political entrepreneurs may misuse prejudice and ignorance, for example, to justify the exclusion of minority groups from access to important resources. In the course of escaiating conflicts such politicised social differences are used to justify amoral action against segments of society. While social difference may be an important ingredient in conflict dynamics it is, however, very rarely the dominant source of violent conflict. The assumption that "social conflict" needs to be seen in relation to other conflict arenas has been reinforced by the research.

In the rural regions researched social issues were not identified as primary conflict arenas. Issues relating to youth, tension between the generations, issues regarding new dynamics in gender relations, and issues concerning exclusion and discrimination against identity groups of ethnic, religious, or regional belonging did, however, surface as secondary conflicts during the research. Since they were not identified as main cross-the-board conflict arenas the material is less consistent.

\footnotetext{
${ }^{51}$ defined for example by generation, gender or social strata

52 ethnic, religious, or regional belonging
} 
Below we will discuss the results on the three fields in turn but treat them as one arena, namely social conflict.

\subsubsection{Youth}

The deprivation of the younger generation of life-opportunities (which the generation of their parents had taken for granted) is a serious and common problem in the postSoviet parts of the research region. Deindustrialisation, deteriorating education standards, the absence of local salaried employment opportunities and the widespread retreat into subsistence or survival family farming has left the younger generation with little opportunity but continuing subsistence farming or seeking work migration. The dominant concern and social obligation of a young man, i.e. founding and supporting a family of his own, is very difficult to fulfil under these conditions. There is a marked change in the prestige economy between the generations with young people increasingly turning away from both Soviet and traditional local values and positions of authority. There are three new types of prestige that fill this "orientation-gap": symbols of western hedonism, spiritual guidance offered by religious, mostly Islamic movements, and the prestige of local political big men, combining material wealth, political power and private enforcement capacity at local level.

Differences and tension between the generations rarely lead directly to open social conflict. The research in Kyrgyzstan and Tajikistan established two different scenarios that show how the problems outlined above might link up to disruptive or violent conflict.

In Batken, diminished prospects and life-opportunities for young people after school combined with the general diminishing social control by traditional authoritative figures, has led to a rise in common youth violence and "antisocial" behaviour (as with the example of dismantling essential infrastructure for quick returns). Apparently, there are cases were disorientation and the search for new sources of prestige have been exploited by new kinds of "social mobilisers", seeking support for their own ambitions. This may form new relationships of dependency of the patronclient type (as in the above mentioned case of the Jany Jer NGO digging a disputed canal) and changing patterns of mobilisation for collective action that would be beyond state or social control. This in turn poses a risk of escalating resource conflicts between communities to new, unchecked levels. 
The case of Navdi in the Rasht valley, Tajikistan (see text box) points to another pattern of aggravated social conflict. The conflict between an informal leader of the local youth and a middle aged informal religious authority (mullo) has been locally perceived as a disgrace for the whole community. The escalation marks two possible social breaking points of rural Tajik society: (1) growing resistance of the younger generation to a system that incapacitates them and excludes them from participation in social and political decision making; and (2) mutually exclusive life-plans with contradictory concepts of prestige among the younger generation - the hedonist, materialist concepts looking to Russia or the West, and the spiritualism of religion and tradition.

In the rural research regions of Tajikistan these conflicts appear to be re-surfacing only just recently since their violent expression came to an end with the peace accord of 1997.

In Afghan Badakhshan the research did not identify issues of youth and generation as particularly critical. In rural areas the traditional decision-making power resides unquestioned with the older male generation. ${ }^{53}$ Nonetheless, the social dynamics in Afghan Badakhshan since the fall of the Taliban has put dramatic pressure on the adaptation of tradition and customs. The younger generation is vital for bringing about successful adaptation of traditional society. In this context a worrying finding of the research is that in many rural communities particularly the young are increasingly dependent on income from cultivation and trade of opium poppies. Decisive enforcement and interdiction against the opium poppy economy (which is in itself desirable) would push young men towards work-migration and endanger their vulnerable social standing in a gerontocratic (domination by the older generation) community order.

A positive potential of young people within social conflict dynamics is identified in the Wakhan district. Here, particularly the younger generation supports the Shah of

\footnotetext{
${ }^{53}$ This assertion must be to some extent be seen relatively, many local commanders are commanders of the $3^{\text {rd }}$ generation, i.e. In their 30 s to 40 s.
} 
Panja in his efforts to put moral and material pressure on drug addicts to stop consumption. In Wakhan (like in many gerontocratic societies with a tradition of drug consumption) consumption is traditionally a privilege of older men and women and addiction is therefore more widespread among older people. Contrary to common Western experience, here it is the young who morally mobilise against drug consumption of their elders.

\subsubsection{Gender}

Women in rural Afghan Badakhshani society are traditionally very significantly disempowered. Their role as actors in public conflict processing is therefore limited to non-existent. Women are, however, very often the subjects of conflict since collective family honour is inseparably linked to the control that male family members exercise over their female dependants and their honour. Family honour can be lost when women are attacked, insulted or when they misbehave. Awareness of women's rights, of discrimination and also of the "opportunity costs" that traditionalism burdens on development appears to be on the rise at least in the urban context of Faisabad and particularly among young people, both men and women. This still very fragile tendency draws on previous, relatively liberal periods in the urban centres of the region. So far it has not led to any visible signs of social tension or conflict.

While the trend in Afghan Badakhshan with regard to the position, rights and opportunities of women is, if anything, an upward one (aibeit from an extremely low starting point) the trend in Tajikistan is instead a downward one, but from a comparatively high starting point that is owed to Soviet modernisation. Lifeopportunities for women in rural areas have dropped disproportionally with the near total disintegration of Soviet infrastructure in rural areas. Particularly affected are spheres that were in Soviet times dominated by women such as education and medical services. Lack of access to information, poor education and a drastic drop in both social and physical mobility, affect all women in Shurabad and Rasht, and women are more and more confined to female spheres of work. Social action is restricted to the household and neighbourhood. It should be noted, though, that gender relations in GBAO are different and women participate much more actively in social and even political life on a community level. It also seems that society in GBAO is much more flexible in adapting to new gender roles than society in Shurabad and Rasht is.

While the situation is perceived as very unfortunate by many women and psychological pressure is mounting (reflected, for example, in rising suicide rates among young women in particular) the connection to potential social conflict beyond the household level is far from clear.

Gender issues were not identified as pressingly relevant for the conflict arenas analysed in Batken oblast. 


\subsubsection{Minorities \& Discrimination}

Like gender and generation related conflicts, discrimination against minorities had been on the initial research agenda in all three countries. During the research, discrimination against minority groups was found to be relevant in very few cases. In those cases discrimination was linked to existing entrenched prejudice, wartime dynamics of conflict and, most topically, to questions of access to scarce resources.

In the case of Afghan Badakhshan incidents of discrimination by majority religious communities against minority settlements were found. However, in the context of Afghan Badakhshan the term minority and majority cannot be defined by province wide statistics on the distribution of ethnic and religious groups. In the present research the unit of analysis was the sub-district (manteqa) and the question of what constitutes a minority has to be set in relation to this unit. Minority settlements of Ismailis in Khustak, for instance, may be discriminated against in their access to pastures by surrounding Sunni villages simply because as a local minority they are less likely to organise effective resistance. If they did it would be easier to mobilise against them as "others", drawing on existing prejudice and an uneasy relationship in that particular manteqa (Khustak) during the insurgence against Communist rule. On the other hand, in a region dominated by Ismailis ("dominated" here not only refer to numbers: the question of to whom the local commander belongs may be crucial), other minority groups may be disadvantaged.

In Tajikistan discrimination has an impact on the social and physical mobility of people from the so-called former opposition regions. This issue is most pressing with regard to the Rasht valley. Seasonal or permanent work-migration for the landless and dispossessed to relatively resource rich "government" regions appears to be simply blocked. Hence, it may be argued that prejudice and discrimination do have a direct impact on other conflict arenas, namely on land tenure and access to alternative income.

Discrimination takes place on the grounds of regional belonging and regional differences that were politicised and entrenched by mass violence during the Civil War. It is fuelled by widespread prejudice, fear, memory of war and misinformation. It should be noted that the official ideology is based on the idea of national accord and is explicitly anti-regionalist. In practice, however, career options for the more ambitious residents of "opposition" regions depend on access to patronage via cooptation.

\section{Conflict transformation - measures available}

Conflict transformation with regard to gender, generation and minority relations is a complex issue devoid of any quick fixes. These relations are deeply entrenched in powerful tales of culture and tradition. Any attempts to foster change in these 
relations will find that they change only very slowly and incrementally; they are fortified against quick adaptive change by the symbolic power of culture.

This by no means claims that family relations, gender relations and concepts of belonging do not change over time. It is just much more difficult to stimulate controlled change by means of development programmes. The ambivalent fate of massive social engineering to this regard, undertaken by the Soviet Union, may illustrate this point. While the (compulsory) integration of women into the workplace, education, sport and public positions unquestionably brought about the significant empowerment of women, this empowerment - particularly in rural places - stopped short of penetrating the private, i.e. family space. De facto polygamy, arranged marriages, abduction of brides, hefty kalym (bridewealth) were all but uncommon in many parts of Soviet Central Asia. This, again, does not mean that Soviet social engineering did not bring about changes within the family - the changes were uncontrolled and progressed often not in the direction intended. Sometimes local traditional institutions targeted by Soviet modernisation measures proved rather adaptive and went successfully underground (like polygamy), criminal (e.g. blood feuding) or penetrated local bureaucracy (nepotism, patronage, regionalism).

Advancing conflict transformation in the region via strategies targeting the changing relations between the generations, between the sexes and between identity groups can be successful if they are long-term and focus on modest achievable goals.

First, it is essential to pick up local society where it is, rather than confronting local communities with arcane approaches to modernisation. All target areas, including Afghan Badakhshan, have their own historic experience with periods of modernisation to connect to. Adapted modernisation, i.e. modernisation that is sensitive to local culture, is nothing new to the communities in the target regions.

May be the most important incentive for individuals in traditional societies to engage in changing traditional patterns of social organisation is the feeling of participation in shaping ones own future - the awareness of life-opportunities must be connected with the awareness of the need for change.

Education is key in influencing awareness of life opportunities. This is why not only the infrastructure aspect of education should be targeted by development programmes but also curriculum development and boy-girl and poor-rich ratios in school attendance. Obviously, this should be done in close co-operation with - or even via - the responsible state institutions. This is particularly important in areas where religious schooling is a cheap and accessible contender for the education of the young (male) generation. AKF has accumulated significant experience in this field that should be used.

Cultural mobility pays for the more flexible part of society when social change becomes an integrated part of life plans of significant parts of the younger generation. In other words, rising awareness of the opportunity costs of traditionalism on the side of young people entering adult society fosters social change. This process concurrently increases pressure on the gatekeepers of 
traditionalist meaning and puts their authority into question. Social conflicts over prestige and influence within families and communities are inevitable. Development programmes cannot avoid and should not prevent such dynamics but they can contribute to a controllable and peaceful transition by facilitating discussion and providing realistic opportunities and guidance for the ambitions of the "young social reformers".

An important asset that helps brining around change may be the provision of structured meeting environments for young people. Such environments bridge the gaps between members of different gender, religious and ethnic identities and foster exchange of information, contacts and awareness of shared ideas, plans and problems. The implementation of such a strategy, for example in the form of youth centres, is possible in the former Soviet regions but appears very difficult for Afghan Badakhshan. In contrast to Kyrgyzstani and Tajikistani society, Afghan Badakhshan has no (Soviet) history of youth, sports and cultural centres as meeting environments for young people of both sexes outside the watchful eye of the family.

Lastly, the research identified two traditional coping strategies that have a negative impact on conflicts about resources. These are, firstly, settlement patterns that infringe physical mobility (like the mahalla/neighbourhood institution replacing impersonal services of local self-government). Secondly, high birth rates, ranging from an average of three to six children in the research region. We discuss these two problematic issues here because part of the cure lies in bringing about changes that directly affect deeply rooted notions of gender roles and identity.

Large families and a strong reliance on neighbourhood solidarity are strategies of risk diversification and make sense in work intensive agriculture. Today, this strategy is a dead end for development; it aggravates pressure on resources, and poses the risk of adding to conflict escalation. Fostering, where feasible, the creation of sustainable income alternatives (e.g. food processing, trade, and small industries in Batken oblast) and more secure, better informed and prepared (work and permanent) migration within the country have to be part of an integrated strategy.

Education and awareness raising are a crucial precondition for bringing around changes with regard to these two issues. Family planning and birth control, though very delicate issues in traditionalist, rural and Muslim communities, must be part of an integrated strategy of conflict transformation.

In the process of changing the core institutions of society - family and kin relations in particular - social tension is inevitable. To counter moral disintegration or a rise in common violence, youth violence in particular, conflict must be channelled and controlled. Obviously, it cannot be checked by traditional social control ("prestige of the old men"). At the same time it would be unfortunate if conflict control were to fall under the new informal social control available ("prestige of the big men"). The only reasonable alternative - aside from the rather distant model of self-policing western civil society - is a neutral and indifferent Leviathan: the state. 


\section{Recommendations for an integrated strategy on conflict transformation in the Programme region}

\subsection{Recommendations for activities in the Programme region}

Recommendations on concrete measures and activities for targeting conflict transformation in the individual programme areas are given in the country reports. Here we focus on the measures important for advancing an integrated strategy for the whole Programme.

\subsubsection{Donor capacity building, enhancing the effectiveness and synergy of development initiatives targeting conflict transformation}

Evidence presented in this study clearly indicates that successful conflict transformation needs a sophisticated level of co-ordination and co-operation among donors active in the same field. Specifically, it is recommended that donors working on conflict in the same target region:

$\rightarrow$ identify and reach agreement on key strategic goals with regard to conflict transformation and establish a shared code of conduct for reaching these goals;

$\rightarrow$ identify and reach agreement on the lead agencies in certain arenas/fields of local conflict transformation (e.g. UNDP for general donor co-ordination; WB for irrigation water in Kyrgyzstan; OSCE and SDC on interregional state and civil society co-operation respectively in the Ferghana region). The identified lead agencies should have at least the moral right to veto project implementation in their sphere of responsibility;

$\rightarrow$ co-ordinate their activities with other donors (agreement on the division of responsibility and the division of labour);

$\rightarrow$ regularly and systematically exchange information with other donors on their strategies and project implementation with regard to conflict transformation (starting with a best practice survey of recent initiatives); institutionalising this exchange is helpful (e.g. regular meetings or the appointment of liaison officers with clearly defined tasks);

$\rightarrow$ agreement on the institutionalisation of co-ordination and procedure in case of disagreements. Donor relations and disagreements should follow the five principles of conflict transformation in good governance 
(negotiation - procedure - formalisation - monitoring - sanction $1+$ transparency).

Recommending enhanced donor co-ordination for the sake of effectiveness is nothing new. When conflict transformation is explicitly targeted it is essential, however. We are aware that there are "the usual" constraints working against the above listed recommendations on the ground: lack of human resources; lack of finances within organisations to establish regular in-house liaison capacities; lack of will to concede responsibility and decision making power to agreed lead agencies; inbuilt institutional donor logic with bottom-up internal organisation accountability and top-down strategic planning with little room for creative inter-donor negotiation and agreement on the ground.

With regard to conflict transformation as a (new) target for development programmes, there is an additional and even more serious difficulty working against the successful donor co-ordination of strategies and activities. Unlike gender or ecological sensitivity, conflict transformation is not yet a mainstream aspect of planning and implementation aside from (mostly lip-service to) do-no-harm checks. Hence, there is no common ground even within individual donor organisations on what targeting conflict transformation actually means in the context of development and aid co-operation. This study identifies conditions under which community driven development initiatives, irrespective of whether their goals included conflict management as a target, actually do foster conflict transformation. The case is made for the institutionalisation and formalisation of Village Organisations in Tajikistan, Shuras in Afghanistan and Water User Associations in Kyrgyzstan. ${ }^{54}$ However, these approaches to conflict transformation are new. What is more, during the research it became evident that the implementation partners of GTZ in Afghan Badakhshan, Tajikistan and even Batken (where GTZ itself is the implementing institution) were far from sure of what result five of the programme i.e. conflict transformation - actually meant. Also, what activities were expected and, indeed, useful in conflict transformation or whether targeting latent conflicts with the tools of food security interventions was even a good idea. Local office leaders in Afghan Badakhshan, for instance, made it quite clear that they felt the conflict aspect of the Programme was imposed upon them - and this is why they successfully lobbied to downgrade result five to an activity under result four, i.e. community development. ${ }^{55}$ While other partners in Tajikistan and Kyrgyzstan might

\footnotetext{
${ }^{54}$ Some major donors which have been involved in community driven development for years are now researching how far their community development programmes were actually conductive to conflict transformation. The World Bank in Indonesia has just commissioned a long-term research project focussing on the question of whether their community driven projects actually not only avoid harm but even do good in terms of conflict management and stability.

${ }^{55}$ See appendix p. 7-47; note: the offer of AKF to GTZ (AKF January 2003) lists result community development and cooperation as result two while in the original offer of GTZ to BMZ (Fastenau 11.11.2002) this result is listed as result four.
} 
have been less explicit, the problem is the same - dealing with conflict as a development target is by no means a currently established routine.

In this study, the effort of conceptualising what good conflict and what bad conflict were in relation to development and how both can be targeted was made. It would be naïve, though, to expect that all the agencies involved would willingly subscribe to the approach outlined and applied here. Nevertheless, without long and constructive dispute neither gender nor ecology would have become more or less consensual mainstream issues in the programming and implementation of development and aid co-operation; discussions about the right approach to conflict are only just taking shape.

\subsection{2 "Soft" measures}

The research revealed that conflict about issues of food security (availability, access and utilisation of natural resources), power (local modes of governance) and meaning (social conflict, immaterial resources) are widespread in the programme region. An important finding of the research is that not only competition and scarcity themselves make bad conflict, it is also the lack of organisational capacities to deal with competition over scarce resources, power and meaning. Institutionalised conflict processing, needs to facilitate transparent and power "unlocked": (1) negotiations between involved parties; (2) agreed procedures to reach decisions; (3) formalisation of decisions (written contracts); (4) neutral monitoring of decision implementation, and (5) credible sanctions against cheating or rule breaking. Such are the institutional cornerstones of conflict transformation, i.e. good conflict.

In order to strengthen conflict transformation in the target region we therefore recommend focusing on the following strategic fields of action:

$\rightarrow$ Identify local institutions processing conflicts and assess their functionality in terms of conflict transformation. The tools of conflict and institutional analysis applied in this research can be used for focussed local assessments. If such institutional arrangements exist and if they are in line with the law and general moral principles they should be backed and built upon. Particularly for functional local informal institutions, the formalisation of procedures, rules and contractual arrangements in writing and the publication/distribution of such proceedings should be facilitated.

$\rightarrow$ Identify formal institutional responsibility for conflict resolution and stick to it even if those official institutions are flawed with weaknesses and undermined by the real power of informal parallel structures (like networks of patronage in Tajikistan or the rule of commanders in Afghanistan). Participating in "muddling through", even if 
more effective in the short run, means participating in undermining official institutional responsibility.

$\rightarrow$ Continue backing institutionalised conflict transformation on the community level and support upgrading its relevance to the district level, connecting local institutional functionality in a meaningful way to the institutional responsibility of the state. The creation of jointly administered district development funds could be such a strategy. Thus local lobbying for better performance of the state at a district and regional level could be fostered.

$\rightarrow$ Institutional capacity building for conflict transformation should focus on existing local state and community institutions (like the Wolliswolli, the Jamoat, the Ail Okmoter, Shuras; Water User Associations with Dispute Resolution Committees, Village Organisations) rather than donor dependent local NGOs. NGOs as donor extensions are simply not sustainable in the role of mediators, facilitators and are less efficient as conflict transforming institutions. With regard to conflict transformation, their capacities should instead be built on conflict analysis, do-no-harm analyses and project management. Customer orientation is key for sustainability. The customers of existing local institutions are the communities; the main customer of donor dependent NGOs is (and usually remains) the donor community.

$\rightarrow$ Invest in awareness raising, information and training as important aspects of making organisational changes work. Communities must understand why changes in the organisation of resources are necessary and how those changes are in their best interests. It is also crucial to raise awareness of the value of formerly state administered resources (in the post-Soviet context). Local ownership is, in part, a question of formal legal entitlement, but it is also a question of understanding and feeling responsibility.

$\rightarrow$ Promote awareness of birth control and family planning in combination with measures targeting education, youth and women's rights as well as women's health. This can be done utilising ongoing or future investment in infrastructure like hospitals, schools and structured meeting environments for young people (see below). Population pressure on limited or simply insufficient natural resources is a root cause of tension that can lead to conflict. In the parts of the Programme region characterised by mountain economies (which is most of the target area, except for parts of Batken oblast) this is a principal problem and it requires unconventional and innovative approaches to food security and conflict transformation measures (see next point).

In addition to ongoing "classic" food security targets (agriculture, infrastructure, access to markets, SME, backing local self-government) long- 
term initiatives directly linked to conflict transformation should be further explored as potential targets. They are:

$\rightarrow$ Backing existing coping strategies, particularly seasonal workmigration. This important and developed coping mechanism within diverse livelihood strategies needs further investigation. Related back-up strategies which deserve further study and potentially reinforcement could include: establishing a fair and reliable system for credit; providing access to information on market requirements; providing vocational training for skills required; and enhancing communication and infrastructural conditions.

$\rightarrow$ Backing safer options for "voice", particularly fostering lobbying and collective action capacities on the side of dependent farmers/sharecroppers and the landless rural population vis-à-vis traders and creditors (in Afghan Badakhshan) or new local latifundists (former entrepreneurs of violence, big men, turned big landowners, as in the Rasht valley, Tajikistan). Helping the more dependent part of the population to better organise the representation of their interests would be particularly important in enhancing alternative livelihood strategies after a successful interdiction in Badakhshan. It should be stressed, however, that raising the organisational capacities of dependent and powerless groups bares the risk of socially disembedded conflict and usually is conditioned on a state framework providing a monopoly of violence and the rule of law. Otherwise empowering the disempowered can go very wrong for the latter. Of the Programme region, only in Batken oblast are such conditions (nearly) met.

$\rightarrow$ Backing civilian alternative livelihood strategies for former entrepreneurs of violence. ${ }^{56}$ Former commanders that have demobilised and are now establishing themselves as businessmen and investors set a good example to others that have got used to making a living (at least in part) by the gun.

\subsection{3 "Hard" measures}

This study shows that the impact of material and technical assistance on conflict transformation (or escalation for that matter) is determined very often by (a) the effectiveness of donor co-ordination and (b) organisational development making technical improvements possible in the first place and sustainable in the long run. Using material measures and technical improvements as incentives for organisational and institutional development is the most promising approach to improving local conflict transformation capabilities. This is not to say that any

\footnotetext{
${ }^{56}$ This is particularly relevant for Afghan Badakhshan since in Tajikistan this target group is either in power, has been co-opted into power or has been destroyed. In Batken. Kyrgyzstan, this problem does not exist.
} 
change can be "bought". Awareness raising, lobbying opinion makers, and integrating existing local institutions in the process are as important as material and technical incentives.

$\rightarrow$ Invest in the identification of technical and material prerequisites for enhancing the institutional cornerstones of conflict transformation. Particularly the monitoring of formal agreements may require technical investment (e.g. for monitoring the extraction of irrigation water, the demarcation of borders, communications between official monitors). If the necessary investment is not within the activity sectors of the Programme, investigate co-operation possibilities with other donors.

$\rightarrow$ Train and equip institutions identified as functional in constructive conflict processing or conflict transformation.

$\rightarrow$ Conditionally grant technical improvement of irrigation water distribution as an incentive for those communities capable of and willing to formalise and advance the organisation of access and distribution as an intercommunal effort. Here the strategy should be to award good performance and community initiative rather than substitute problems caused by a lack of initiative.

$\rightarrow$ Continue investing in the relaxation of pressure on the key resource of arable land by improving agricultural income through know-how transfer, better technology, introduction of cash-crops, making available or improving existing credit systems, and the institutionalisation of agricultural extension services. Boosting income from agriculture in regions without land tenure security and bad (powerlocked) local governance might, however, increase pressure on land and foster a concentration of land ownership. The tendency of the concentration and accumulation of land to impact on economic development and bad conflict (violence or disruption) has to be closely monitored. Under such circumstances withdrawal, ideally co-ordinated with other major donors, must be a seriously considered option.

$\rightarrow$ Create sustainable income alternatives to survival and subsistence agriculture. This is the only sustainable alternative to the unorthodox recommendation on available coping strategies of (seasonal) exit and collective voice for those who cannot make a living on (even improved) agriculture. Trade, small production and the refining of local produce should be central targets. Obviously, the marketability of the product and access to markets have to be checked and if possible improved for such measures not to backfire with regard to conflict transformation.

$\rightarrow$ Use the rehabilitation of education and medical infrastructure as a trust building measure and as a basis for targeting development messages. Hospitals and rural medical points are good places for 
awareness raising on issues concerning women's health and family planning; the curricula of schools can include civic awareness, responsibility in the utilisation of scarce resources and the like. The content of education also has a direct impact on non-agricultural lifeopportunities for the young generation. Co-operation with responsible state agencies and international donors engaged in the field of curricular development and awareness raising could be a fruitful approach.

$\rightarrow$ Back the creation or rehabilitation of structured meeting environments for young people. Contact between young people beyond the narrow confines of kin-relations and the local neighbourhood is very limited, particularly in a rural and traditional context. If contact does take place it is unstructured and often conflict prone. Structured meeting environments, which were made available by the Soviet Union, are now defunct (sports centres, culture and youth clubs and cinemas even in the villages). In Afghan Badakhshan there is no tradition of institutionalising contact between young people of different communities. Influencing the value orientation, interest, knowledge and social capabilities of young people is an essential investment of society in its own (peaceful) future. This awareness should be propagated and local initiatives, which do exist, should be backed. Otherwise this field will be left uncontested to religious entrepreneurs potentially targeting the young, disillusioned generation.

$\rightarrow$ Check if co-operation with responsible government institutions on facilitating the voluntary re-settlement of young families from communities with unsustainable population pressure on available resources is feasible and not harmful. For some communities permanent migration or resettlement is the only option. Great care has to be taken that resettlement does not produce human and development catastrophes by mismanagement or outright betrayal by the responsible government agencies (as in the case of the encouraged resettlement from GBAO to a wasteland in western Khation in Tajikistan in the late 1990s).

\subsubsection{Understanding conflict and using information for planning and project adaptation}

It always appears suspicious when external analysts argue the necessity of further investigation and analysis. This report also does this, but only to a certain extent. It is important, however, to stress that whatever can be achieved locally should be achieved locally. It may be necessary to build up these local capacities further. 


\subsubsection{Local and internal capacity building}

\section{$\rightarrow$ Build capacities for focused ad hoc conflict and peace potential analysis}

A number of conflict arenas identified for the target regions are very vulnerable to escalation. Any development activities targeting such arenas should first conduct a local conflict analysis of the target communities. Such arenas are for instance the distribution of water in border regions in Batken, local governance in Afghan Badakhshan and Tajikistan; land tenure in Afghan Badakhshan, and in the Rasht and the Shurabad regions of Tajikistan.

When the declared goal of development activities is strengthening the capacities for conflict transformation, a thorough conflict analysis in the target communities of projects or initiatives is required. Gathering and analysing local knowledge on conflicts cannot be done across the board by one study like the current one. Local differences and dynamic change over time have to be captured by community-based project development.

The capacity for such "analyses on demand" should be built in GTZ local implementing partner organisations. A first step has been taken in the framework of this research, which introduced and applied tools of information gathering on conflict and methods of analysis. Without further guided application of the tools, however, capacity building will not be accomplished.

Additionally, capacities for overseeing and appreciating such analysis should be advanced within the local GTZ organisational structure. Hiring a project assistant with expertise in the field has been a good start. Analytical capacities and guidance in fieldwork should be further developed.

Guidance and supervision by GTZ is of utmost importance so that local targeted analysis is done without bias to the capacity and focus of the donor organisation. Otherwise it is highly likely that food security focused donors will receive analyses of various conflicts as being poverty or food-insecurely related, while human right focused donors would be informed that conflicts were discrimination related. ${ }^{57}$ Analysis has to be open to results that discourage intervention by donors with a certain profile - for example, because the causes and dynamics of conflicts prove to be beyond the capacities of the donor. GTZ should have the in-house expertise to make sure how far identified and analysed local conflicts can be targeted with activities available under results 1-5/6 are adequately evaluated.

\footnotetext{
${ }^{57}$ On the problem of donors making sense of conflicts in a biased and reductionist manner see Goodhand, Atkinson 2001: 31 .
} 
$\rightarrow$ Internal capacities must be built to routinely conduct local do-noharm checks before implementing projects working in or on conflict.

A meaningful do-no-harm check in the Programme region must account for four problems of unintentionally getting involved with bad conflict: (1) is there a risk that the project might get dragged into an existing conflict? (2) Is the project stabilising arrangements of local governance that are clearly bad for long-term development? (3) Are the initiatives replacing core local state functions in an institutional sense or are they competing with them? And (4) is donor competition and the lack of donor co-operation itself an example of bad governance and an arena for local conflict?

Based on a do-no-harm check, it would be possible to make informed decisions on when it is time to get out and when it is better not to move in.

In real life no pre-implementation analysis can account for all unfortunate impacts and eventualities. This is why standard operational procedures for all staff members engaged in implementing Programme funded projects should be developed together with the partner organisations. These procedures should inform the implementation and monitoring units on how to proceed when they find that unintentional harm is done. Pre-structuring such measures relieves local staff of the difficult and at times dangerous responsibility of freedom to decide on what action to take.

\subsubsection{Further research needs for strategy development and for mainstreaming} approaches to conflict transformation within the context of food security

The research identifies the following critical gaps in our understanding of linking food security focused development with conflict transformation:

$\rightarrow$ Of mountain economies and alternative livelihoods: are active exit (migration) and voice (mobilising protest and collective lobbying) strategies ways of coping that are a necessary part of conflict transformation in the mountain economies under scrutiny?

$\rightarrow$ Of land tenure: Is it possible to consolidate economic development with conflict transformation under conditions of land concentration and accumulation by power elites?

$\rightarrow$ Of local governance: can functional, community-based, non-state governance (VO, Shura, WUA) (a) gain from linking up to district state government? And can the local state institutions (b) have a positive impact on the performance of community capacities in conflict transformation (formalisation, scope of binding decision, sanction) and therefore at the same time boost its own legitimacy? 
$\rightarrow$ Of measuring success and failure: the development of smart indicators for an impact assessment of complex community driven development strategies on conflict transformation, irrespective of whether they were explicitly designed to target conflict transformation (like investing in local self-government).

\subsection{Recommendations on regional cooperation and regional stability}

\subsubsection{Potentials and limits of regional cooperation in the context of conflict transformation}

Most conflicts today take place within social and political entities in which individuals, networks, communities, companies and political institutions did communicate and co-operate with each other before violent conflict escalation. The former Soviet Union is a showcase in which the most vicious conflicts did not happen between Union Republics (with their comparatively limited and insignificant direct co-operation because of the centralised command system that took decisions and channelled resources) but within these Republics.

Regional co-operation per se is therefore not an indicator, much less a tool, for reliable non-violent conflict processing. The quality of co-operation (communal, political, economic, informal, criminal) and particularly the level of institutionalisation of co-operation have to be measured in order to predict their impact on conflict processing.

\subsubsection{Geographical re-orientation of target regions for regional co- operation}

We recommend separating the strategic approach of the Programme towards regional co-operation as a conflict preventing initiative into two distinct focal areas: (1) the Ferghana valley as viewed from Batken province (including the bordering Uzbek and Tajik provinces and enclaves); and (2) the border districts between Afghanistan and Tajikistan. Both from a cross-border perspective on conflict transformation and on food security focused development co-operation, these regions require different approaches. What is more, the threats that appeared to link the target regions of the Programme in the three countries - i.e. regional spillover of instability from Afghanistan through Tajikistan into Kyrgyzstan through armed incursions and the proliferation of arms, radical Islamism, drugs and terrorist violence - are no longer acute. Fragile stability in Tajikistan depends, to a significant extent, on successful state-building in Afghan Badakhshan. This problem is best 
targeted with a focus on the southern Tajikistan and northern Afghanistan border regions. The cross-border impact on conflict and development in the Batken oblast of Kyrgyzstan, on the other hand, has to be targeted in the context of the border regions and the Uzbekistani and Tajikistani exclaves in the Ferghana valley. Here, regional co-operation and competition is the main issue while co-operation or threats form the Tajik regions across the Turkistan mountain ridge has been and will be strictly limited.

\subsubsection{Ferghana / Batken}

The main concern for conflict transformation is (a) the irrational patchwork arrangement of bubbles of sovereignty for the three states; (b) political manipulation and corrupt misuse of the border regime; and (c) the lack of effective cross-border institutional arrangements to solve local conflicts locally.

Lobbying for the professionalisation of border control, avoiding the political and economic misuse of check points and limiting their number should all be done only in close co-ordination with organisations of regional diplomatic standing, i.e. UNDP and OSCE.

The functionality of existing cross-border institutions - like the Parity Committee charged with demarcation related issues - is important for easing tensions and resolving conflicts and must be backed in any way possible. Thus far, there are hardly any official institutions capable of negotiating in cross-border conflict cases. Contact is usually established via informal local institutions before officials get involved. However, ad hoc mediation works and the possibility of institutionalising cross-border mediation and conflict resolution should be further explored. The meaningful involvement of local state institutions with decision-making power is particularly crucial for the success of such initiatives.

A parallel strengthening of contact between civil society actors, community leaders and other respected figures should be sought and co-ordinated with donors already experienced in this field (SDC, OSCE).

In terms of border related problems, civil society can, however, only be a back up to changes that require the political will of governments in order to ease tension and find sustainable solutions to conflicts. The latter is beyond the scope of food security and conflict management development approaches. Lobbying the German government to encourage the political will in all three countries of the Ferghana valley to resolve border issues permanently, and connecting to lead agencies with diplomatic influence is therefore an important precondition to any direct involvement in the politics of border regimes.

\subsubsection{Afghan-Tajik border regions}

On the Afghan-Tajik border there are two main threats to cross-border stability. (1) The failure of state building in Afghanistan and resumption of civil war; and (2) 
the uncontrolled effects of relaxing the border regime and encouraging contact between the border communities.

The first issue is of obvious regional political importance and can only be targeted to a limited extent by local development programmes. Making the new state work on the ground and contributing to rather than contesting its legitimacy are core principles suggested in this report.

The second issue - the effects of border opening and intensifying cross-border contact - puts local development to the fore.

Investing in the smart opening of borders as an alternative to the dangerous, illegal trespassing usually associated with trafficking and criminal activity is a crucial priority for development and security in the region. This certainly involves investment in technical hardware and infrastructure beyond the capacities and focus of the Programme - like building bridges, training and equipping border checkpoints, and building up border infrastructure on the Afghan side from scratch. Particularly with the predicted replacing of border guards under Russian command with Tajik border forces; the security concerns of border villages will be aggravated.

Smart border opening is not only a technical and infrastructure problem. Social and economic risks and opportunities should be the main focus of the development initiatives in the Programme. Fear of well-organised armed groups involved in drug trafficking is also an important feature of the way border communities currently relate to their neighbours. Except for the established criminal cross-border networks, there appear to be no institutional arrangements to regulate conflicts arising. Donor interventions and NGO activity should target both the lack of trust and the institutional gap. Institutionalisation of well-organised and strictly controlled border markets could be a step in the right direction. Intensifying the transfer of technical skills and know-how from the Tajik side to communities in Afghan Badakhshan via NGO activity would also be well received. This should also include the experience of GBAO with moral campaigning on the community level against drug production, trafficking and consumption. The extension of such a campaign to religious authorities and state agencies would be important in Afghan Badakhshan. Since security risks for border communities on the Tajik side appear to depend to a significant extent on the poor or even criminal performance of state agencies (border guards, police and judiciary involved directly or indirectly in the drug trafficking economy) maximum pressure should be exercised on the Tajik and Russian governments to bring the situation under control. Such measures are clearly beyond the scope of the Programme but international agencies with diplomatic weight should be backed and the German government should be lobbied to put this problem on the agenda of intergovernmental negotiations. This is particularly important in the light of the extension of the ISAF mandate to the northeastern provinces of Afghanistan, and the extension of the GTZ Programme to Kunduz, Takhar and Baghlan. Takhar and Kunduz border the Khation region of Tajikistan, a region that, though under strict central control, is said to have taken over as the main drug trafficking route since Russian border guards tightened their 
grip on the Gorno Badakhshan section of the border. The efficiency of measures against the opium poppy economy in those regions of Afghanistan depend to some extent on discouraging the pull-factor of easy trafficking across parts of the Tajik border.

\subsection{Recommendations on PCIA}

\subsubsection{Impact Monitoring, measuring, adapting}

Peace and Conflict Impact Assessment (PCIA) is a systematic approach to institutionalise conflict analysis, impact monitoring and the adaptation of projects. programmes and strategies in the project cycle management process.

The central question of PCIA is ${ }^{58}$ whether the project enhances peaceful conflict processing or whether it obstructs it. In this regard, PCIA is closely related to do-noharm principles and assessment methods. However, the functions of PCIA reach much further. They include a) a progress review of all project objectives in relation to conflict transformation; b) the observation and analysis of intended and unintended interaction between conflict developments and the project; c) capacity building for project staff and partner organisations on understanding conflict in the framework of development initiatives; d) improving transparency and accountability with respect to target groups and clients throughout the project; and e) introducing adjustment or replanning measures in the project if necessary.

Monitoring the impact of development projects on local peace and conflict is critical for programmes explicitly targeting conflict transformation. Measuring the negative effects of projects on conflict escalation is difficult because most conflicts are multicausal and dynamic. Observing and analysing interdependencies rather than attempting to measure them in quantitative terms is, however, much easier. In fact a do-no-harm analysis includes such qualitative measurements, and there is an established routine for checking causal links between project activity and any negative events that take place (conflict escalation). Establishing, let alone measuring, the causal links between project activities and peace (in the sense of absence of conflict) is much more difficult. Such a task would amount to measuring an event that did not take place, i.e. a conflict that did not take place but would have taken place in the absence of the project.

In this study we therefore suggested a different understanding of peace and conflict. What can be observed and at least in part measured is good conflict processing. The task is to develop medium rage indicators that can be observed in order to measure good conflict processing by analysing the cornerstone functions of conflict

${ }^{58}$ Leonhardt 2001: 13 
transformation, particularly decisions made, decisions implemented, monitoring applied and sanctions taken.

$\mathrm{PClA}$ is a serious long-term investment and requires time, financial and human resources in order to be integrated into programming. The GTZ Programme and its implementation partners are involved in activities that take place in a conflict prone environment. What is more, these activities themselves may be of a conflictive nature, such as, for example, empowering existing local institutions, building new institutions in order to make local self-organisation more efficient and reducing informal control over communities. Therefore, a constant assessment of the interaction between concrete development initiatives and conflict processes could be a useful component of the Programme strategy in the regions. Since PCIA is resource intensive, a careful cost and benefit analysis must be conducted.

Based on the results of this study the following tentative recommendations can be made:

$\rightarrow$ There is no urgent need to implement a fully-fledged PCIA in the Ferghana part of the programme area (Batken). Focused conflict analysis on demand and do-noharm checks for activities in the most sensitive conflict arenas identified above would appear to be sufficient for time being.

$\rightarrow$ For Tajikistan, PCIA should be treated as a serious option on the agenda of the implementation partner MSDSP. Focused conflict analysis on demand, risk appraisals and impact indicator development shouid be further refined and treated as a possible foundation for potential institutionalisation of a PCIA if needed. Fullscale establishment of PCIA should be a strategic option but not immediate task for the time being. PCIA would be of more urgent need if MSDSP decided to expand as an organisation rather than to focus and limit their activities to service provision. PCIA would be critical with the expansion of activities into the following fields: (1) the expansion from resource poor to resource rich regions (Khatlon); (2) cushioning the impact of opening borders with Afghanistan and replacing Russian border troops with local forces; (3) extending the community level and linking up with local government; (4) land tenure issues in Rasht and Shurabad.

$\rightarrow$ Afghan Badakhshan: the step-by-step institutionalisation of a fully functional PCIA system is strongly recommended because of (1) a very dynamic and vulnerable situation with regard to conflict and development; (2) the existing decision on longterm engagement of AKDN in the target region as well as the long term commitment of the international community as a very likely prospect; (3) the existence of serious long-term risk factors.

PCIA consists of four steps: 1) conflict analysis, 2) risk appraisal, 3) impact assessment, and 4) adaptation. The Programme has invested considerably in conflict analysis and the results are at hand. The heart of PCIA is, however, the continuous impact assessment of measures taken on the ground. It includes 
conflict monitoring, impact hypothesis, case studies and participatory impact assessment. Where a decision to implement PCIA is made, developing indicators for monitoring programme impact on good conflict (peaceful development) and bad conflict (violence and disruption), allocating responsibility within the Programme and implementation partners for monitoring and evaluation tasks, and setting up procedures for the processing of information received are the next steps to be taken. 


\section{References}

AKF (January 2003), Aga Khan Foundation - Proposal to GTZ for funding. Badakhshan: enhancing food security in Upper Panj area and its hinterland, AKDN, Aga Khan Foundation (AKF).

Anderson, Mary B. (1999), Do no Harm, Boulder, CO,Lynne Reinner Publishers Inc.

BB (2004), 'Uzbekistan imposes high fees on Kyrgyz highway transit', RFE/RL Newsline 16.01.04, online publication, http://www.rferl.org/newsline/2004/01/2TCA/tca-160104.asp (26.01.2004).

BBC Monitoring (2004), 'Southern Kyrgyz authorities grappling with problem of Uzbek road transit charges', BBC Monitoring Service 23.01.2004, www.securities.com (31.01.2004).

BMZ (07.04.2000), Krisenprävention und Konfliktbeilegung, BMZ Spezial 17, Bundesministerium für wirtschaftliche Zusammenarbeit und Entwicklung, Bonn, http://www.bmz.de/infothek/fachinformationen/spezial/spezial017/spezial017_90.pdf (11.01.2004).

BMZ (18.12.2001), BMZ-Zentralasien-Konzept, Referat 201, Bundesministerium für wirtschaftliche Zusammenarbeit und Entwicklung, Bonn, http://www.bmz.de/themen/ArbeitRegionen/Zentralasien-Konzept.pdf (11.01.2004).

Barron, Patrick; Diprose, Rachael; Madden, David et al. (September 2003), Do Participatory Development Projects Help Villagers Manage Local Conflicts? A Mixed Methods Approach to Assessing the Kecamatan Development Project, Indonesia, Social Development Department, Environmentally and Socially Sustainable Development Network, CPR Working Papers, http://Inweb18.worldbank.org/ESSD/sdvext.nsf/60ByDocName/DoParticipatoryDevel opmentProjectsHelpVillagersManageLocalConflictsCPRWorkingPaperNo9/\$FILE/C PRWP9-Methodology201003.pdf.

Berg, Christoph (September 2003), Drugs and Conflict. Discussion Paper by the GTZ Drugs and Development Programme, Drugs and Development Programme, Deutsche Gesellschaft für Technische Zusammenarbeit (GTZ), Eschborn.

Bundesregierung (18.03.2002), Zentralasienkonzept der Bundesregierung, German Federal Government, Berlin, http://www.auswaertiges-

amt.de/www/de/infoservice/download/pdf/asien/zentralasienkonzept.pdf (11.01.2004).

Bundesregierung (1998), Koalitionsvertrag. Erneuerung - Gerechtigkeit Nachhaltigkeit. Für ein wirtschaftlich starkes, soziales und ökologisches Deutschland. Für eine lebendige Demokratie, http://www.bundesregierung.de/Anlage444120/Koalitionsvertrag+zwischen+SPD+un 
d+B\%fcndnis+90/Die+Gr\%fcnen+vom+16.+Oktober+2002.pdf (02.12.2003).

Coser, Lewis A. (1956), The Functions of Social Conflict, London, Routledge \& Kegan Paul.

Cramer, Christopher and Goodhand, Jonathan (2002), 'Try Again, Fail Again, Fail Better? War, the State, and the 'Post-Conflict' Challange in Afghanistan', Development and Change, 33: 5, 885-909.

Elwert, Georg (2003), 'Intervention in Markets of Violence', in J. Koehler and C. Zürcher (ed.), Potentials of disorder, Manchester, Manchester University Press.

Eurasianet.org (2003), 'Border troop controversy underscores Tajik-Russian tension', EURASIA INSIGHT 07.10.03,

http://www.eurasianet.org/departments/insight/articles/eav100703a_pr.shtml (08.03.2004).

Fastenau, Axel (11.11.2002), Angebot zur Durchführung des Vorhabens Förderung von Ernährungssicherheit, regionaler Kooperation und Stabilität in AfghanBadakhshan. Projekt Auftragsnummer 2002.3654.7, Deutsche Gesellschaft für Technische Zusammenarbeit (GTZ), Eschborn.

Fastenau, Axel (20.06.2002), Angebot zur Durchführung des Vorhabens Förderung von Ernährungssicherheit, regionaler Kooperation und Stabilität in der Region Garm und dem Distrikt Shurabad in Tadschikistan. Auftragsnummer 2002.3652.1, Titel 687 08, Deutsche Gesellschaft für Technische Zusammenarbeit (GTZ), Eschborn.

Freizer, Sabine and Abdullaev, Kamoludin (2003), Strategic Conflict Assessment Taiikistan, GCPP; UK Government, Dushanbe.

Glatzer, Bernt (2003), Länderstudie über Krisenprävention und Friedensförderung in Afghanistan, Gesellschaft für Technische Zusammenarbeit; Friedrich Ebert Stiftung, Eschborn (January 2003).

Goodhand, Jonathan and Atkinson, Philippa (2001), Conflict and Aid: Enhancing the Peacebuilding Impact of International Engagement. A Synthesis of Findings from Afghanistan, Liberia and Sri Lanka, International Alert, London, http://www.international-alert.org/pdf/pubdev/Synthrep.pdf (05.12.2003).

Government of the Kyrgyz Republic; UNDP (2003), Kyrgyzstan/Taiikistan. CrossBorder Conflict Prevention Project. Project Number: KYR/03/005, Security Council, Government of the Kyrgyz Republic; United Nations Development Programme, Bishkek (?).

Grävingholt, Jörn (22.03.2003), Krisenpotenziale und Ansatzpunkte für eine krisenpräventive deutsche Entwicklungszusammenarbeit in Zentralasien, Deutsches Institut für Entwicklungspolitik (DIE), Bonn.

ICG (2001, March), Central Asia: Islamist Mobilisation and Regional Security, International Crisis Group, Osh/Brussels, ICG Asia Report: 14.

ICG (2001, November), Afghanistan and Central Asia: Priorities For Reconstruction and Development, International Crisis Group, Osh/Brussels, ICG Asia Report: 26.

(a) 
ICG (2001, November), Central Asia: Drugs and Conflict, International Crisis Group, Osh/Brussels, ICG Asia Report: 25. (b)

ICG (29.09.2003), Peacebuilding in Afghanistan, International Crisis Group (ICG), ICG Asia Report 64, Kabul/Brussels.

ICG (30.05.2002), Central Asia: Water and Conflict, International Crisis Group, Osh/Brussels, http://www.reliefweb.int/library/documents/2002/icg-uzb-30may.pdf (25.02.2004).

Leonhardt, Manuela (2001), Conflict Impact Assessment for Development Projects. A practical guideline - Draft, Gesellschaft für technische Zusammenarbeit, Eschborn, http://www.gtz.de/crisisprevention/download/impactassessment.pdf (05.12.2003).

Mansfield, David (January 2004), Coping Strategies, Accumulated Wealth and Shifting Markets: The Story of Opium Poppy Cultivation in Badakhshan 2000-2003, AKDN (Agha Khan Development Network).

Pain, Adam (January 2004), The Impact of the Opium Poppy Economy on Household Livelihoods: Evidence from the Wakhan Corridor and Khustak Valley in Badakhshan. A study for the AKDN Badakhshan Programme funded by GTZ, AKDN, GTZ.

Rashid, Ahmed (October 2003), 'Afghanistan. Drugs Are Good for War', Far Eastern Economic Review, 23.10.2003, 21-22.

Robinson, Sarah and MSDSP, (2002), Land reform and land tenure in the Rasht region, Mountain Societies Development Support Programme and Aga Khan Foundation, Garm.

Tarzi, Amin (2004), '20 Die In Clashes Between Warlords In Northern Afghanistan.That Official Blames On Narcotics Turf War', Azadi Radio 09.02.2004, www.azadiradio.org/aspfiles/functions/en_print.asp (05.03.2004).

Vecherniy Bishkek (2004), 'Tajik seizure of land in Kyrgyz border village prevented', Eurasianet 03.03.2004, http://www.eurasianet.org/recources/tajikistan/hypermail/news/0000.shtml (03.03.2004).

Wily, Liz Alden (March 2003), Land Rights in Crisis: Restoring Tenure Security in Afghanistan, AREU (Afghanistan Research and Evaluation Unit), Issues Paper Series, Kabul/Islamabad. 